\title{
Colonic proteome signature in immunoproteasome-deficient stressed mice and its relevance for irritable bowel syndrome
}

Alexis Goichon ${ }^{1,2}$, Wafa Bahlouli ${ }^{1,2}$, Ibtissem Ghouzali1 ${ }^{1,2}$, Philippe Chan ${ }^{2,3}$, David Vaudry ${ }^{2,3,4}$, Pierre Déchelotte ${ }^{1,2,5}$, Philippe Ducrotté ${ }^{1,2,6 \dagger}$, Moïse Coëffier ${ }^{1,2,5, *}$

${ }^{1}$ Normandie Univ., UNIROUEN, INSERM unit 1073, Rouen, France.

${ }^{2}$ Normandie Univ., UNIROUEN, Institute for Research and Innovation in Biomedicine (IRIB), Rouen, France.

${ }^{3}$ Normandie Univ., UNIROUEN, Platform in proteomics PISSARO, Rouen, France.

${ }^{4}$ Normandie Univ., UNIROUEN, INSERM unit 1239, Rouen, France.

${ }^{5}$ Rouen University Hospital, Nutrition Department, Rouen, France.

${ }^{6}$ Rouen University Hospital, Gastroenterology Department, Rouen, France.

$\dagger$ Deceased

*Corresponding author: Moïse Coëffier - INSERM U1073, UFR Santé, 22 boulevard Gambetta, 76183 ROUEN cedex France - tel +33235148240; fax +33235148226; moise.coeffier@univ-rouen.fr 


\section{ABSTRACT}

A role for immunoproteasome in the regulation of intestinal permeability has been previously suggested both in mice during water avoidance stress (WAS) and in patients with irritable bowel syndrome (IBS). Here, we provide evidence that the ubiquitin-proteasome system (UPS) contributes to the pathophysiology of IBS. Indeed, we report that colonic proteome is altered in WAS mice and that $\beta 2 \mathrm{i}$ subunit deficiency modifies the proteome response that is associated with a limitation of colonic hyperpermeability. Interestingly, we show specific alterations of proteins involved in UPS, mitochondrial and energy metabolism. We also report changes in the pattern of colonic ubiquitome in diarrhea-predominant IBS patients (IBS-D), and particularly a reduced expression of ubiquitinated proteins involved in the NF- $\kappa \mathrm{B}$ inflammatory signaling pathway. All these data suggest that immunoproteasome targeting may represent a new therapeutic strategy for the treatment of IBS patients with increased intestinal permeability.

Keywords: Colonic proteome; Immunoproteasome; Irritable bowel syndrome; Water avoidance stress. 


\section{INTRODUCTION}

Irritable bowel syndrome (IBS) is a functional gastrointestinal (GI) disorder that affects $5-20 \%$ of the general population in industrialized countries. ${ }^{1,2}$ It is characterized by chronic abdominal pain associated with diarrhea and/or constipation, bloating and urgency. ${ }^{3}$ Recent studies have shown that IBS-associated symptoms, such as visceral hypersensitivity, low-grade inflammation or pain, may be linked to disturbances in intestinal barrier function. ${ }^{4-9}$ Alterations were observed in the expression and distribution of intestinal tight junctions (TJs), apical protein structures that control paracellular permeability. ${ }^{10-12}$ Indeed, IBS patients with diarrheapredominant symptoms (IBS-D) exhibited an increased permeability both in $\operatorname{colon}^{13}$ and jejunum $^{12}$, and a reduced expression of several TJ proteins such as occludin, zonula occludens-1 (ZO-1) and claudin-1. ${ }^{11,12}$ Emerging evidence supports the concept of altered colonic ubiquitineproteasome system (UPS) in IBS patients that could be responsible of intestinal barrier dysfunction. Interestingly, occludin has been reported as a functional target of the E3 ubiquitinprotein ligase $\mathrm{Itch}^{14}$ and we have previously shown that the low expression of occludin in the colonic mucosa of IBS patients was related to its higher degradation by UPS. ${ }^{11}$

UPS is a major pathway of proteolysis in eukaryotic cells and may contribute to the regulation of many intestinal biological processes, such as inflammatory response, cell proliferation and apoptosis. ${ }^{10,15,16}$ Targeted proteins by UPS are polyubiquitinated and then processed by the constitutive $20 \mathrm{~S}$ proteasome, which comprises three catalytic subunits named $\beta 1, \beta 2$, and $\beta 5$. In mammals, the exposure of cells to inflammatory cytokines such as IFN- $\gamma$ or TNF- $\alpha$ leads to the formation of an immunoproteasome that can be distinguished from its constitutive homologue through assembly of the catalytic immunosubunits named LMP2 ( $\beta 1$ i), 
MECL-1 ( $\beta 2 \mathrm{i})$ and LMP7 ( $\beta 5 \mathrm{i}) .{ }^{17}$ It has been reported an increased expression of immunoproteasome subunits in intestinal epithelial cell lines stimulated by IFN- $\gamma \cdot{ }^{15,16}$ In vivo, the immunosubunits $\beta 1 \mathrm{i}$ and $\beta 2 \mathrm{i}$ were strongly upregulated in colon tissues of IBS ${ }^{10}$ and Crohn's disease (CD) patients, ${ }^{15}$ but not in patients with ulcerative colitis. Proteasome inhibitors such as bortezomib, MG132 and PR-957 have been developed and have achieved success in preventing experimental colitis in mice. ${ }^{18-20}$ Similar effects have been observed with mice deficient in subunit $\beta 5$ i. ${ }^{19}$ More recently, we showed a link between proteasome and intestinal permeability in mice. In this latter study, both pharmacological immunoproteasome inhibition and $\beta 2 \mathrm{i}$ subunit deficiency limited colonic hyperpermeability and improved occludin expression. ${ }^{21}$

To better understand the underlying mechanisms, we thus aimed (i) to evaluate the colonic proteome in wild-type and $\beta 2 \mathrm{i}$ immunoproteasome subunit knock-out $\left(\beta 2 \mathrm{i}^{--}\right)$mice during water avoidance stress (WAS) and (ii) to investigate the colonic expression of 49 ubiquitinated proteins in IBS-D patients. 


\section{MATERIAL AND METHODS}

\subsection{Animals}

Male C57B1/6 knock-out mice for MECL1 gene (or $\beta 2 \mathrm{i}$ proteasome subunit) were a kind gift from Professors Marcus Groettrup and Mickael Basler of Konstanz University (Germany) with the permission of Professor John Monaco from Cincinnati University (Ohio). The protocol was approved by CENOMEXA, the Ethics Committee of Normandy for Animal Experimentation (acceptance number: N/04-11-12/27/11-15). In addition, all experiments were performed in accordance with relevant guidelines and regulations (Official Journal of the European Community L 358, 18/12/1986) and followed ARRIVE guidelines. ${ }^{22}$

\subsection{Water avoidance stress}

The water avoidance stress (WAS) is a murine model of chronic stress that induces several symptoms associated to IBS. In particular, WAS increased visceral sensibility, colonic motility, intestinal permeability, pro-inflammatory cytokine production and mast cell count. ${ }^{21,23-25}$ After one week of acclimatization at $23^{\circ} \mathrm{C}$ (12-hour light-dark cycle; dark phase: 8:00 PM - 8:00 AM), WAS model was performed during 1 hour per day during 10 consecutive days as previously described. ${ }^{21}$ After the last WAS procedure, mice were euthanized. Colonic samples were either taken, washed with ice-cold PBS and immediately frozen until further analysis or immediately used to evaluate paracellular permeability.

\subsection{Intestinal permeability}


Colonic permeability was evaluated by measuring paracellular flux of FITC-dextran (4 kDa) through colonic samples mounted in Ussing chambers as previously described. ${ }^{26}$ Briefly, FITCdextran $(5 \mathrm{mg} / \mathrm{ml})$ was placed in the mucosal side. After 3 hours at $37^{\circ} \mathrm{C}$, medium from the serosal side was removed and stored at $-80^{\circ} \mathrm{C}$. The fluorescence level of FITC-dextran was measured in 96-well black plate with spectrometer Chameleon V (excitation at $485 \mathrm{~nm}$, emission at $535 \mathrm{~nm}$; Hidex, Turku, Finland).

\section{4. $\quad$ qRT-PCR}

Mucosal total RNA was extracted from samples as previously described. ${ }^{27}$ After reverse transcription of $1.5 \mu \mathrm{g}$ total RNA into cDNA by using 200 units of SuperScript ${ }^{\mathrm{TM}}$ II Reverse Transcriptase (LifeTechnologies, Cergy-Pontoise, France), qPCR was performed by SYBR ${ }^{\mathrm{TM}}$ Green technology on BioRad CFX96 real time PCR system (BioRad Laboratories, Marnes la Coquette, France) in duplicate for each sample. GAPDH was used as the endogenous reference gene. Specific primers are displayed in Table S-1.

\subsection{Proteasome activities}

Proteasome activities were evaluated on colonic mucosa homogenized in ice-cold lysis buffer containing $30 \mathrm{mM}$ Tris- $\mathrm{HCl}(\mathrm{pH}$ 7.2), $1 \mathrm{mM}$ dithiothreitol, $1 \%$ Triton $\mathrm{X}-100$ by spectrofluorimetry on microtiter plate fluorometer Mithras LB 940 (Berthold Technologies, Bad Wildbad, Germany) as previously described. ${ }^{10}$

\subsection{Protein extraction for comparative proteome and ubiquitome analysis}


Colonic mucosa were homogenized, as previously described, ${ }^{\mathbf{2 8 , 2 9}}$ in ice-cold lysis buffer containing $7 \mathrm{M}$ urea, $2 \mathrm{M}$ thiourea, 4\% (wt:vol) CHAPS, $50 \mathrm{mM}$ dithiothreitol, $25 \mathrm{mM}$ spermine tetrahydrochloride, 1X protease inhibitor cocktail (P2714; Sigma Aldrich) and 0.5\% (vol:vol) IPG buffer with pH 3-10 non-linear (GE Healthcare). The protein content was determined by using 2D Quant kit (GE Healthcare).

\subsection{Comparative proteome analysis}

Total protein extract (40 $\mu \mathrm{g}$ for silver staining or $500 \mu \mathrm{g}$ for CBB G-250 staining) was used to rehydrate Immobiline DryStrip gels (pH 3-10 NL 18 cm; GE Healthcare). Proteins were resolved in the first dimension by isoelectric focusing for a total of $50000 \mathrm{~V}$-h by using the Ettan IPGphor 3 (GE Healthcare). After equilibration of the strips, the second dimension was performed on $8-16 \%$ polyacrylamide gradient gels $(20 \mathrm{~cm} \times 18 \mathrm{~cm} \times 1 \mathrm{~mm})$ and was run on an Ettan Daltsix vertical system (GE Healthcare). The 2D gels were silver-stained (PlusOne Silver Staining kit; GE Healthcare) for image analysis or dyed following the CBB G-250 staining method for mass spectrometric analysis. ${ }^{28}$

\section{(i) 2 D image Analysis}

Silver stained gels were scanned with an ImageScanner II (GE Healthcare) previously calibrated by a greyscale marker (Kodak) and 2D images were captured with Labscan 6.00 software (GE Healthcare). Differential analysis was realized by using ImageMaster 2D Platinum v7.0 software (GE Healthcare) for spot detection, background subtraction, spot volume normalisation and differences in spot expression among the groups and/or each experiment. Each tissue sample was subjected to $2 \mathrm{DE}$ three times to minimize run-to-run variation, and each set of 
three gels was compared by using ImageMaster to confirm the nonappearance of statistically differential spots within the set of gels. The most representative silver-staining gels (gel migration, spot definition, and spot number) of each sample ( $n=5$ per group) was used to identify differential colonic protein expression. The expression level was determined by the relative volume of each spot in the gel and expressed as \%volume, calculated as spot volume/ 2 volumes of all spots resolved in the gel. Variations in abundance, corresponding to normalized spot volume, were calculated as the ratio of average values of \%volume for each group. Only spots with a \%volume variation $>1.4$ were included in analysis. Statistical differences between the groups were determined using ANOVA (significance level $P$ values $<0.05$ ).

\section{(ii) In-gel trypsin digestion and protein identification by LC-ESI-MS/MS}

Protein spots of interest were manually excised from colloidal Coomassie blue-stained 2D gels and digested. Briefly, gel fragments were washed three times for $20 \mathrm{~min}$ in destaining solution containing $50 \%(\mathrm{v} / \mathrm{v})$ methanol and $50 \mathrm{mM}$ ammonium bicarbonate. The excised spots were then air-dried for $1 \mathrm{~h}$, which was followed by in-gel digestion in $30 \mu \mathrm{L}$ of a digestion buffer containing $50 \mathrm{mM}$ ammonium bicarbonate and $6 \mathrm{ng} / \mu \mathrm{L}$ sequencing grade bovine trypsin (Roche Diagnostics, Meylan, France). After overnight digestion, the aliquots were treated with $50 \%$ (v/v) acetonitrile and $5 \%(\mathrm{v} / \mathrm{v})$ formic acid. Speed-vas-dried peptide extracts were resuspended in $10 \mu \mathrm{L}$ of $5 \%(\mathrm{v} / \mathrm{v})$ acetonitrile and $0.1 \%(\mathrm{v} / \mathrm{v})$ formic acid and then analyzed with a nanoflow liquid chromatograph LC1200 system coupled to a Q-TOF 6550 mass spectrometer equipped with a nanospray source and an HPLC-chip cube interface (Agilent Technologies). A 20-min linear gradient (3-75\% acetonitrile in $0.1 \%$ formic acid), at a flow rate of $350 \mathrm{~nL} / \mathrm{min}$, was used to separate peptides on a polaris-HR-Chip C18 column (150 mm long $\times 75 \mu \mathrm{m}$ inner diameter). 
Full autoMS1 scans from 290 to $1700 \mathrm{~m} / \mathrm{z}$ and autoMS2 from 59 to $1700 \mathrm{~m} / \mathrm{z}$ were recorded. In every cycle, a maximum of 5 precursors sort by charge state $(2+$ preferred and single-charged ions excluded) were isolated and fragmented in the collision cell that was automatically adjusted depending on the $m / z$. Active exclusion of these precursors was enabled after 1 spectra within $0.13 \mathrm{~min}$, and the absolute threshold for precursor selection was set to 1000 counts (relative threshold $0.001 \%$ ). For protein identification, MS/MS peak lists were extracted and compared with the protein databases using the MASCOT Daemon version 2.4.0 (Matrix Science, London, UK) search engine. The MASCOT searches were performed in Mus musculus database as previously described. ${ }^{30}$ Protein hits were automatically validated if they satisfied one of the following criteria: identification with at least two top ranking peptides (bold and red) each with a MASCOT score of more than $41(P<0.001)$, or at least two top ranking peptides (bold and red) each with a MASCOT score of more than $31(P<0.01)$. To evaluate false-positive rates, all the initial database searches were performed using the "decoy" option of MASCOT. Results were considered relevant if the false-positive rate never exceeded $1 \%$. The mass spectrometry data were deposited in the ProteomeXchange Consortium via the PRIDE partner repository (https://www.ebi.ac.uk/pride/archive/) with the data set identifier PXD011199 and 10.6019/PXD011199. ${ }^{31}$

\subsection{Patients}

Fourteen patients, who met the Rome III criteria for IBS with predominant diarrhea and seen in the Department of Gastroenterology of the Rouen University Hospital, were included between December 2012 and July 2016 (10 women/4 men, aged $41.2 \pm 11.2$ years). IBS patients with the following criteria were excluded: (i) patients with IBS predominant constipation or alternating 
constipation and diarrhea, (ii) blood dyscrasia, (iii) personal history of auto-immune disease, (iv) personal history of inflammatory bowel disease, (v) personal history of digestive cancer, or (vi) macroscopic (except for diverticulosis, hyperplasic polyp, and angiodysplasia) and histological abnormality of the colonic mucosa. Fourteen control patients ( 8 women/6 men, aged $55 \pm 17.4$ years) were subjects admitted in the Department of Gastroenterology of the Rouen University Hospital for a colonoscopy indicated within the framework of screening (anemia, personal or family history of polyp, family history of colorectal cancer, rectal bleeding, screening campaign). To be selected, control subjects had to fulfill all of the following criteria: (i) macroscopically and histological normal colonic mucosa (diverticulosis, hyperplasic polyp, and angiodysplasia were tolerated), (ii) lack of any digestive symptom, and (iii) lack of any organic or functional bowel disease. A complete colonoscopy was performed under general anesthesia after large bowel cleansing with $4 \mathrm{~L}$ of a macrogol solution. Biopsies were taken in the descending colon in all cases. Two biopsies for each patient were analyzed by a pathologist in order to exclude any histological abnormality. Written informed consent was obtained from each patient. The protocol was conducted in accordance with the Declaration of Helsinki and European GCP for biomedical research.

\subsection{Ubiquitome analysis}

Expression of 49 ubiquitinated proteins was assessed using the commercially Proteome Profiler $^{\mathrm{TM}}$ Human Ubiquitin Array kit (R\&D Systems, Abingdon, UK) according to the manufacturer's instructions. Briefly, $300 \mu \mathrm{g}$ of colonic mucosal proteins were loaded on membranes previously coated with specific antibodies directed against ubiquitinated proteins. After incubation of these membranes with specific buffers and wash steps, ubiquitinated proteins 
were detected using ECL reagents (GE Healthcare). Each spot was quantified by densitometry using ImageScanner III and ImageQuant TL software (GE Healthcare). Only spots with a \%Vol variation ratio greater than 1.5 were considered relevant.

\subsection{Gene ontology-based analysis}

The PANTHER classification system (version 10.1, http://www.pantherdb.org) was used to categorize the identified proteins according to their molecular function and biological process. To identify significantly enriched biological themes and functional groups in the list of identified proteins, functional annotation clustering analysis was performed using the DAVID Gene Ontology (GO) tool version $6.7^{32}$ as previously described ${ }^{30}$ with minor modifications: the reference dataset were Mus musculus or Homo sapiens, and $P<0.05$ for Benjamini-Hochberg correction was considered significant.

\subsection{Western blot analysis}

$20 \mu \mathrm{g}$ of total protein extracts were separated by $4-20 \%$ SDS-PAGE gels and electrotransferred onto nitrocellulose membrane (GE Healthcare) as previously described. ${ }^{28}$ Membrane was blocked with 3\% (wt:vol) BSA in TBS-T solution [10 mM Tris-HCl pH 7.4, $150 \mathrm{mM} \mathrm{NaCl}$, 0.2\% (vol:vol) Tween 20] and then incubated with corresponding primary antibodies overnight at $4^{\circ} \mathrm{C}$ : mouse monoclonal antibodies anti-UCH-L3 (sc-100340, 1:2500); goat polyclonal antibodies anti-GDH1 (sc-160382, 1:1000) or anti-HSP60 (sc-1052, 1:3000); rabbit monoclonal antibodies anti-Ub (sc-9133, 1:1000) from Santa Cruz Biotechnology. Membrane was washed three times for 10 min with TBS-T and then incubated with appropriate horseradish peroxidasecoupled secondary antibodies [HRP-goat anti-mouse IgG (sc-2005, 1:5000; Santa Cruz Biotechnology), HRP- donkey anti-goat IgG (sc-2020, 1:5000; Santa Cruz Biotechnology), 
HRP-swine anti-rabbit IgG (P0399, 1:5000; Dako)] for $1 \mathrm{~h}$ at room temperature. After 2 washes with TBS-T, immunocomplexes were revealed by using ECL detection reagents (GE Healthcare). Protein bands were quantified by densitometry with ImageScanner III and ImageQuant TL software (GE Healthcare). The blot was stripped and reblotted with a mouse monoclonal antibody anti $\beta$ actin (A5441, 1:5000; Sigma Aldrich) also used as a loading control.

\subsection{Detection of carbonylated Proteins}

Carbonylated proteins were detected and analyzed following derivatization of protein carbonyl groups with 2,4-dinitrophenylhydrazine (DNPH), using the OxyBlot kit (Millipore, Billerica, MA). Briefly, colonic proteins were incubated with DNPH for $15 \mathrm{~min}$ at room temperature to convert carbonyl to hydrazone derivatives. The samples were neutralized and applied on SDS-

PAGE and transferred to nitrocellulose membranes. Immunodetection was performed with a primary antibody directed against dinitrophenylhydrazone.

\subsection{Statistical analysis}

Results were compared in GraphPad Prism 5.0 (GraphPad software Inc, San Diego, CA, USA) by two-way ANOVA (stress x $\beta 2 \mathrm{i}^{--}$) with Bonferroni post-tests. To data from patients, t-test or Mann-Whitney test were used as appropriate. For all tests, $P<0.05$ was considered significant. 


\section{RESULTS}

3.1. Immunoproteasome subunit beta2i deficiency prevents hyperpermeability and proinflammatory cytokine production in the colonic tissue of stressed mice

The WAS model increased fecal pellet output from day 1 to day 10 both in wild-type (wt) and $\beta 2 \mathrm{i}^{-/-}$mice (Figure S-1A). However, $\beta 2 \mathrm{i}^{-/-}$WAS mice showed lower fecal pellet output than wt WAS mice. In $\beta 2 \mathrm{i}^{-/-}$mice, trypsin-like activity was not affected by WAS (Figure S-1B). Interestingly, colonic mRNA levels for TNF- $\alpha$ and IL- $1 \beta$ were not altered in $\beta 2 \mathrm{i}^{-{ }^{-}}$WAS mice (Figure S-1C). Gut barrier function was assessed by paracellular permeability of FITC-dextran. WAS induced enhanced passage of FITC-dextran across the colonic mucosa of wt mice (Figure S-1D). Interestingly, FITC-dextran flux was markedly reduced in $\beta 2 \mathrm{i}^{-/-}$WAS mice compared to wt WAS mice (Figure S-1D). These data confirm that WAS did not affect colonic permeability in $\beta 2 \mathrm{i}^{-/-}$mice, as previously described. ${ }^{21}$

\subsection{WAS and immunoproteasome subunit beta2i deficiency alter colonic proteome in} mice

To evaluate colonic proteome and then identify altered biological processes in wt and $\beta 2 \mathrm{i}^{- \text {- }}$ mice both in control and WAS conditions, we used a proteomic approach combining 2DE mapping and mass spectrometry identification. Image analysis detected approximately 2100 protein spots per 2D gel, out of which $75 \%$ were successfully matched throughout all gels. Representative 2D gels from both conditions are shown in Figure 1A. Fifty protein spots were differentially and significantly expressed between the four mice groups (at least \pm 1.4 fold change; two-way ANOVA, $\mathrm{p}<0.05)$. These protein spots were analyzed by using liquid chromatography coupled 
with electrospray ionization MS/MS, and 36 spots (72\%) were identified (Table 1). Overall, 33 non-redundant proteins were obtained. Indeed, two proteins, named MICOS complex subunit Mic60 (spots 2 and 4, Figure 1A) and protein disulfide-isomerase precursor (spots 14, 16 and 17; Figure 1A), were detected at multiple spot positions that could be due to protein isoforms, i.e. difference in maturation state, degradation and/or post-translational modifications. Among the identified proteins, 22 proteins were downregulated in the colonic mucosa of wt WAS mice compared with wt mice, while only 6 proteins were affected by WAS in $\beta 2 \mathrm{i}^{-/-}$mice. Interestingly, among these 6 proteins, only 2 were downregulated. In addition, we also observed that 7 proteins were differentially expressed in $\beta 2 \mathrm{i}^{-/-}$WAS mice compared to wt WAS mice. In this latter case, proteasome subunit alpha type-3 (PSMA3), proteasome subunit alpha type-5 (PSAM5) and ubiquitin carboxyl-terminal hydrolase isozyme L3 (UCH-L3) were up-regulated in the colonic mucosa of $\beta 2 \mathrm{i}^{--}$WAS mice (range from 2.20 to 3.80 -fold), whereas proteasome subunit alpha type-4 (PSMA4), alpha-enloase 1 (ENO1), $60 \mathrm{kDa}$ heat shock protein (HSP60) and glutamate dehydrogenase 1 (GDH1) showed a reduced expression (with fold changes from 1.48 to 1.86).

To validate the data from proteomics experiments, three proteins were randomly selected to verify the expression level via Western blot analysis (Figure 2A). The colonic expression levels of GDH1 and HSP60 were downregulated in $\beta 2 \mathrm{i}^{-/-}$WAS mice compared to wt WAS mice, whereas UCH-L3 expression was increased, which is consistent with the results given by 2-DE analysis, and thus confirmed the proteomic findings.

\subsection{WAS and immunoproteasome subunit beta2i deficiency modify expression of protein involved in mitochondrial and energy metabolism in the colon}


Panther Gene Ontology (GO) analysis allowed us to elucidate the different functions and processes in which the 33 proteins identified are putatively involved. According to the molecular function analysis (Figure 1B), most of the proteins were related with catalytic activity $(53.1 \%)$ and binding $(18.8 \%)$. Concerning biological processes, the identified proteins were mainly involved in metabolic process (45.5\%, Figure 1B). To expand the GO analysis, we next analyzed the proteomic data with DAVID functional annotation tool. DAVID uses GO and other data sources to cluster proteins based on the shared annotations to similarity clusters. DAVID analysis identified 3 significant annotation clusters (Table 2), of which the highest ranked cluster had an enrichment score (ES) of 4.89 and was represented by 3 terms relating to mitochondrion.

The mitochondrial cluster accounted for $33 \%$ of the identified proteins and included: ATP synthase subunit beta (Atp5b), Elongation factor G1 (EF-G1mt), Elongation factor G2 (EFG2mt), Electron transfer flavoprotein subunit alpha (ETFA), GDH1, HSP60, Heat shock protein 75 (HSP75), Isovaleryl-CoA dehydrogenase (IVD), MICOS complex subunit (Mic60), 3mercaptopyruvate sulfurtransferase (MST), Vacuolar protein sorting-associating protein 4B (Vsp4b). The expression levels of Atp5b, EF-G1mt, EF-G2mt, HSP75, IVD, Mic60, MST and Vsp4b were downregulated in the colonic mucosa of wt mice during WAS (Figure 3). It was also observed a decreased expression of pyruvate kinase (PKM), adenylosuccinate synthetase isozyme (Adss2) and adenosine kinase (AK), which are involved in energy metabolism (Figure 3). These data suggest a significant decrease of mitochondrial activity and energy metabolism in the colonic mucosa during WAS. Invalidation of $\beta 2 \mathrm{i}$ expression alone induced similar modifications of colonic proteome except for Vsp4b, Atp5b and AK (Table 1). Interestingly, Vsp4b, Atp5b and AK remained unaffected in $\beta 2 \mathrm{i}^{-/-}$WAS mice compared with $\beta 2 \mathrm{i}^{-/-}$control mice. In addition, in $\beta 2 \mathrm{i}^{---}$mice, WAS altered alpha-enolase-1 (ENO1), which was 
downregulated, and Uridine phosphorylase 1 (UPase 1; Table 1). By comparing the response of wt and $\beta 2 \mathrm{i}^{-/-}$mice to WAS, we observed a reduction of ENO1, HSP60 and GDH1 expression in $\beta 2 \mathrm{i}^{-/-}$WAS mice (Table 1 and Figure 3).

\subsection{WAS and immunoproteasome subunit beta2i deficiency alter ubiquitin-proteasome} system in the colon.

We also observed that proteasome subunits were significantly enriched among identified proteins. The proteasome cluster $(\mathrm{ES}=2.06$, Table 2$)$ was made up from three proteasome alpha subunits (PSMA3/4/5) and 26S protease regulatory subunit S10B (PSMC6). The expression levels of PSCM6 and two others UPS related-proteins, namely pre-mRNA-processing factor (Prpf19) and protein deglycase (DJ-1), were decreased in the colonic mucosa of wt mice during WAS (Figure 4). Interestingly, $\beta 2 \mathrm{i}^{-/-}$WAS mice exhibited an increased expression of PSMA3 and PSMA5 as compared to $\beta 2 \mathrm{i}^{--}$control mice, and of PSMA3, PSMA5 and UCH-L3 when compared to wt WAS mice (Table 1 and Figure 4). By contrast, PSMA4 were downregulated while Prpf19 and DJ-1 remained unaffected in $\beta 2 \mathrm{i}^{-/-}$WAS mice. UCH-L3 is a deubiquitinating enzyme (DUB) that controls levels of cellular ubiquitin through processing of ubiquitinated proteins. We thus evaluated the level of ubiquitinated proteins in the colonic mucosa and we observed that both wt and $\beta 2 \mathrm{i}^{-/-}$control mice exhibited a reduction of ubiquitinated protein levels in response to WAS (Figure 2B). Interestingly, $\beta 2 \mathrm{i}^{-/-}$WAS mice exhibited lower ubiquitinated protein level than wt WAS mice. All these data suggest that (i) WAS affected UPS and (ii) that subunit $\beta 2 \mathrm{i}$ deficiency may regulate the degradation of specific proteins. 
3.5. Ubiquitination of inflammation-related proteins is modulated in the colonic mucosa of IBS-D patients

Because stressed mice exhibited UPS changes in their colonic mucosa, we investigated in IBS-D patients the putative changes of ubiquitination of colonic proteins. For this purpose, we used macroarrays directed against 49 ubiquitinated proteins. Among these 49 proteins, the expression of 7 ubiquitinated proteins was significant decreased in the colonic mucosa of IBS-D patients compared with control patients (Figure 5): TNF- $\alpha$-induced protein 3 (A20), Prostaglandin G/H synthase 2 (COX-2), Heat shock $70 \mathrm{kDa}$ protein (HSP70), Heat shock protein HSP 90 (HSP90), Interferon regulatory factor 3 (IRF3), Nuclear factor erythroid 2-related factor 2 (Nrf2), TNF receptor-associated factor 6 (TRAF-6). Nevertheless, the total expression of ubiquitinated proteins was not significantly different between control and IBS-D patients (Figure S-2A). Interestingly, enrichment analysis of KEGG pathways in DAVID showed that A20, COX-2, IRF3 and TRAF6 were involved in the NF-אB signaling pathway (39.7-fold enrichment, $\mathrm{p}=0.031$ ). All these data suggest that ubiquitination of these proteins may participate in the pathophysiology of IBS-D, which is commonly described as a low grade inflammatory state, by regulating apoptosis and disrupting UPS mechanism. 


\section{DISCUSSION}

In the present study, we provide evidence that the ubiquitin-proteasome system contributes to the pathophysiology of IBS. Indeed, we report that colonic proteome is altered in stressed mice and that $\beta 2 \mathrm{i}$ subunit deficiency modifies the proteome response that is associated with a limitation of colonic hyperpermeability. Interestingly, we show specific alterations of proteins involved in UPS, mitochondrial and energy metabolism. We also report changes in the pattern of colonic ubiquitome in IBS-D patients, and particularly a reduced expression of ubiquitinated proteins involved in the NF- $\mathrm{KB}$ signaling pathway.

Previous studies clearly demonstrated that UPS may be involved in the regulation of inflammatory response ${ }^{33}$ or gut barrier function ${ }^{10}$. We and others have reported the formation of an alternative proteasome called immunoproteasome in the colonic mucosa of $\operatorname{IBS}^{10}$ and $\mathrm{CD}^{15,34}$ patients. It was also shown that proteasome composition and activity were different between CD and IBS patients. ${ }^{10}$ Indeed, trypsin-like activity was increased in the colonic mucosa of IBS patients ${ }^{35}$ but not in CD patients. By contrast, chymotrypsin-like activity remained unchanged in IBS patients whereas it was upregulated in CD patients. In the present study, we used a stress model (the water avoidance stress "WAS" model) able to reproduce certain aspects of IBS such as visceral hypersensibility or intestinal hyperpermeability. Indeed, stress contributes to the development and aggravation of IBS symptoms. ${ }^{36}$ WAS mice exhibited an increase colonic permeability, trypsin-like activity and $\beta 2 \mathrm{i} / \beta 2$ subunit ratio, ${ }^{21}$ that was previously observed in IBS-D patients. ${ }^{10}$ In our study, we showed that $\beta 2 \mathrm{i}$ subunit deficiency increased expression of proteasome subunits (PSMA3/5) in stressed mice, whereas PSMA4 and ubiquitinated proteins was downregulated. The shift from constitutive to immunoproteasome could be responsible for 
the decrease of ubiquitinated proteins after WAS since Seifert et al. showed that immunoproteasome activity is higher than constitutive proteasome activity. ${ }^{37}$ Nevertheless, Nathan et al. have reported that immunoproteasomes and constitutive proteasomes degraded ubiquitinated proteins at similar rates following IFN $\gamma$-treatment. ${ }^{38}$ Other processes like ubiquitination and deubiquitination may also be involved. UCH-L3, which was increased in $\beta 2 \mathrm{i}^{-/-}$ mice in the present study, is a deubiquitinating enzyme performing hydrolysis of the bond at the $\mathrm{C}$ terminus of the ubiquitin and triming down the polyubiquitin chain into monomers. UCH-L3 knock-out mice led to marked accumulation of ubiquitinated proteins in the skeletal muscles. ${ }^{39}$ However, the effect of UCH-L3 overexpression on ubiquitinated protein level remains unknown. Thus, the underlying mechanisms responsible of the ubiqtuinated protein level changes need to be deeply explored. UCH-L3 also processed an ubiquitin-like substrate called NEDD8 and regulated smad1 ubiquitination in osteoblast differentiation. ${ }^{40}$ Interestingly, Sano et al. have reported that UCH-L3 prevented mitochondrial oxidative stress-related apoptosis in photoreceptor cells. ${ }^{41}$ UCH-L3 may then affect mitochondrial structure and the levels of reactive oxygen species (ROS). By contrast, it was considered as negative regulators of apoptosis in cancer. ${ }^{42-44}$ More interestingly, Zhao et al. have recently underlined a relationship between UCH-L3 and inflammatory response. Indeed, overexpression of UCH-L3 inhibited the activity of cellular $\mathrm{SCF}^{\beta-\mathrm{TrCP}}$ ligase E3 through a limitation of cullin-1 neddylation. ${ }^{45} \mathrm{SCF}^{\beta-\mathrm{TrCP}}$ ligase E3 induces ubiquitination and degradation of phosphorylated substrates including $\mathrm{I}-\mathrm{\kappa B}$, the inhibitor of $\mathrm{NF}-\kappa \mathrm{B} .{ }^{46}$

Previous papers reported that NF- $\kappa \mathrm{B}$ activity can also be limited by glutamine through the regulation of $\mathrm{I}-\kappa \mathrm{B}$ ubiquitination ${ }^{29,47}$ and particularly by the regulation of cullin-1 neddylation. ${ }^{48}$ Interestingly, in the present study, we showed that $\beta 2 \mathrm{i}$ subunit deficiency leads to 
a reduced expression of GDH1 in the colonic mucosa of WAS mice. GDH1 is a metabolic enzyme mainly located in the mitochondria that catalyzes the reversible NAD (P)+-linked oxidative deamination of glutamate into $\alpha$-ketoglutarate and ammonia. This reaction is the final step of glutaminolysis after the conversion of glutamine to glutamate by glutaminase. In inflammatory experimental conditions, glutamine supplementation improves gut barrier function $^{49-52}$, regulates UPS ${ }^{29,48,53}$ and restores colonic TJ protein expression..$^{49,50,54}$ We have recently demonstrated that glutamine supplementation prevented colonic hyperpermeability and reduced proinflammatory cytokine production in WAS mice. ${ }^{21}$ Zhou et al. have recently reported that reduced expression of glutamine synthase in colon tissues of IBS-D patients may lead to decreased claudin-1 expression, and consequently increased intestinal permeability. ${ }^{55}$ In the same way, we have shown ex vivo that glutamine supplementation increased claudin- 1 expression in the colonic mucosa of IBS-D patients. ${ }^{54}$ In a randomized controlled trial, Zhou et al recently showed the beneficial effect of glutamine supplementation on intestinal permeability and gastrointestinal symptoms in post-infectious IBS patients. ${ }^{56}$ All these data are in accordance with previous studies showing that glutamine supplementation or deprivation is able to modify $\mathrm{TJ}$ protein expression and influence intestinal permeability..$^{50,57}$ The mechanisms of action for glutamine remain not completely understood and have been previously discussed. ${ }^{58,59}$ In our model, we can thus speculate that immunoproteasome inhibition induces higher glutamine content and overexpression of UCH-L3 leading to limitation of inflammatory response and improved barrier function (Figure 6). The assessment of colonic mucosal glutamine content in $\beta 2 \mathrm{i}^{-/-}$WAS mice should be thus further investigated.

To confirm the putative role of proteasome system in the pathophysiology of IBS, we have investigated in IBS-D patients the changes of ubiquitination rate of colonic proteins. 
Interestingly, we observed alterations of ubiquitome, and particularly a reduced expression of 7 ubiquitinated proteins involved in the NF- $\mathrm{kB}$ signaling pathway. Cleynen et al. previously reported that adherent-invasive Escherichia coli (AIEC) was able to regulate UPS leading to a decrease of NF- $\kappa B$ negative regulator CYLD in intestinal epithelial cells. ${ }^{60}$ In patients with IBSD, Zhou et al. recently underlined that colonic hyperpermeability caused by TNF- $\alpha$ may be due to activation of NF-kB expression and disassembly of claudin-1. ${ }^{55}$ All of these data suggest potential relationship between UPS, glutamine content, inflammatory response and TJ protein expression in the pathophysiology of IBS. Further investigations should be done to deeply explore these mechanisms.

In conclusion, we provide evidence that (i) $\beta 2 \mathrm{i}$ subunit deficiency modified colonic UPS function in stressed mice that was associated with an improvement of intestinal hyperpermeability, (ii) IBS-D patients exhibited altered colonic ubiquitome leading to altered NF- $\mathrm{B}$ pathway. Therefore, immunoproteasome targeting represents a new therapeutic strategy for the treatment of IBS-D patients with intestinal hyperpermeability. 


\section{ASSOCIATED CONTENT}

\section{Supporting Information}

Figure S-1. Colonic permeability and cytokine production in stressed mice.

Figure S-2. Expression levels of ubiquitinated and carbonylated proteins in colonic mucosa of IBS-D patients.

Table S-1. Sequences of used primers for qPCR

\section{ACKNOWLEDGMENTS}

We thank the staff of the Endoscopy Unit for their assistance with the endoscopic procedure. We dedicate this work to the memory of Prof. Philippe Ducrotté, our colleague and friend, who passed away on December 30, 2017.

This work was supported by a Cephalon Research Prize (to IG), by INSERM and the University of Rouen Normandy and co-supported by European Union and Normandie Regional Council (to WB and for equipments). Europe gets involved in Normandie with European Regional Development Fund (ERDF). These funders did not participate in the design, implementation, analysis and interpretation of the data.

\section{AUTHOR CONTRIBUTIONS:}

AG, IG, WB, PC performed experiments and analyses. AG and MC designed experiments. PDu performed colonoscopy and sampling. AG, DV, PDe, PDu and MC interpreted the data. AG and MC wrote the main manuscript text and prepared figures. All authors reviewed the manuscript.

\section{DISCLOSURE STATEMENT:}


The authors declare that they have no conflict of interest.

\section{ABBREVIATIONS:}

A20, TNF- $\alpha$-induced protein 3; Adss2, Adenylosuccinate synthetase isozyme; AK, Adenosine kinase; Atp5b, ATP synthase subunit beta; CD, Crohn's disease; COX-2, Prostaglandin G/H synthase 2; EF-G1mt, Elongation factor G1; EF-G2mt, Elongation factor G2; ENOA, Alphaenolase-1; ETFA, Electron transfer flavoprotein subunit alpha; GDH1, Glutamate dehydrogenase 1; GO, Panther Gene Ontology; HSP60, 60 kDa heat shock protein; HSP70, Heat shock 70 kDa protein; HSP75, Heat shock protein 75 kDa; HSP90, Heat shock protein $90 \mathrm{kDa}$; IBS, irritable bowel syndrome; IBS-D, diarrhea-predominant irritable bowel syndrome; IVD, Isovaleryl-CoA dehydrogenase; IRF3, Interferon regulatory factor 3; Mic60, MICOS complex subunit; MST, 3mercaptopyruvate sulfurtransferase; Nrf2, Nuclear factor erythroid 2-related factor 2; NF- $\mathrm{BB}$, nuclear factor-kappa B; PKM, Pyruvate kinase; Prpf19, Pre-mRNA-processing factor; PSMA3/4/5, Proteasome alpha subunits; PSMC6, 26S Protease regulatory subunit S10B; TJs, tight junctions; TRAF-6, TNF receptor-associated factor 6; UCH-L3, Ubiquitin carboxylterminal hydrolase isozyme L3; UPase 1, Uridine phosphorylase 1; UPS, ubiquitine-proteasome system ; Vsp4b, Vacuolar protein sorting-associating protein 4B; WAS, water avoidance stress; wt, wild-type. 


\section{REFERENCES}

(1) Le Pluart, D.; Sabaté, J.-M.; Bouchoucha, M.; Hercberg, S.; Benamouzig, R.; Julia, C. Functional Gastrointestinal Disorders in 35,447 Adults and Their Association with Body Mass Index. Aliment. Pharmacol. Ther. 2015, 41 (8), 758-767.

(2) Ford, A. C.; Lacy, B. E.; Talley, N. J. Irritable Bowel Syndrome. N. Engl. J. Med. 2017, 376 (26), 2566-2578.

(3) Drossman, D. A.; Camilleri, M.; Mayer, E. A.; Whitehead, W. E. AGA Technical Review on Irritable Bowel Syndrome. Gastroenterology 2002, 123 (6), 2108-2131.

(4) Simrén, M.; Axelsson, J.; Gillberg, R.; Abrahamsson, H.; Svedlund, J.; Björnsson, E. S. Quality of Life in Inflammatory Bowel Disease in Remission: The Impact of IBS-like Symptoms and Associated Psychological Factors. Am. J. Gastroenterol. 2002, 97 (2), 389-396.

(5) Camilleri, M.; Madsen, K.; Spiller, R.; Greenwood-Van Meerveld, B.; Van Meerveld, B. G.; Verne, G. N. Intestinal Barrier Function in Health and Gastrointestinal Disease. Neurogastroenterol. Motil. Off. J. Eur. Gastrointest. Motil. Soc. 2012, 24 (6), 503-512.

(6) Zhou, Q.; Verne, G. N. New Insights into Visceral Hypersensitivity--Clinical Implications in IBS. Nat. Rev. Gastroenterol. Hepatol. 2011, 8 (6), 349-355.

(7) Spiller, R. C.; Jenkins, D.; Thornley, J. P.; Hebden, J. M.; Wright, T.; Skinner, M.; Neal, K. R. Increased Rectal Mucosal Enteroendocrine Cells, T Lymphocytes, and Increased Gut Permeability Following Acute Campylobacter Enteritis and in Post-Dysenteric Irritable Bowel Syndrome. Gut 2000, 47 (6), 804-811. 
(8) Dunlop, S. P.; Hebden, J.; Campbell, E.; Naesdal, J.; Olbe, L.; Perkins, A. C.; Spiller, R. C. Abnormal Intestinal Permeability in Subgroups of Diarrhea-Predominant Irritable Bowel Syndromes. Am. J. Gastroenterol. 2006, 101 (6), 1288-1294.

(9) Zhou, Q.; Zhang, B.; Verne, G. N. Intestinal Membrane Permeability and Hypersensitivity in the Irritable Bowel Syndrome. Pain 2009, 146 (1-2), 41-46.

(10) Coëffier, M.; Gloro, R.; Boukhettala, N.; Aziz, M.; Lecleire, S.; Vandaele, N.; Antonietti, M.; Savoye, G.; Bôle-Feysot, C.; Déchelotte, P.; et al. Increased Proteasome-Mediated Degradation of Occludin in Irritable Bowel Syndrome. Am. J. Gastroenterol. 2010, 105 (5), 1181-1188.

(11) Bertiaux-Vandaële, N.; Youmba, S. B.; Belmonte, L.; Lecleire, S.; Antonietti, M.; Gourcerol, G.; Leroi, A.-M.; Déchelotte, P.; Ménard, J.-F.; Ducrotté, P.; et al. The Expression and the Cellular Distribution of the Tight Junction Proteins Are Altered in Irritable Bowel Syndrome Patients with Differences According to the Disease Subtype. Am. J. Gastroenterol. 2011, 106 (12), 2165-2173.

(12) Martínez, C.; Vicario, M.; Ramos, L.; Lobo, B.; Mosquera, J. L.; Alonso, C.; Sánchez, A.; Guilarte, M.; Antolín, M.; de Torres, I.; et al. The Jejunum of Diarrhea-Predominant Irritable Bowel Syndrome Shows Molecular Alterations in the Tight Junction Signaling Pathway That Are Associated with Mucosal Pathobiology and Clinical Manifestations. Am. J. Gastroenterol. 2012, 107 (5), 736-746.

(13) Zhou, Q.; Souba, W. W.; Croce, C. M.; Verne, G. N. MicroRNA-29a Regulates Intestinal Membrane Permeability in Patients with Irritable Bowel Syndrome. Gut 2010, 59 (6), 775-784. 
(14) Traweger, A.; Fang, D.; Liu, Y.-C.; Stelzhammer, W.; Krizbai, I. A.; Fresser, F.; Bauer, H.-C.; Bauer, H. The Tight Junction-Specific Protein Occludin Is a Functional Target of the E3 Ubiquitin-Protein Ligase Itch. J. Biol. Chem. 2002, 277 (12), 10201-10208.

(15) Visekruna, A.; Joeris, T.; Seidel, D.; Kroesen, A.; Loddenkemper, C.; Zeitz, M.; Kaufmann, S. H. E.; Schmidt-Ullrich, R.; Steinhoff, U. Proteasome-Mediated Degradation of IkappaBalpha and Processing of P105 in Crohn Disease and Ulcerative Colitis. J. Clin. Invest. 2006, 116 (12), 3195-3203.

(16) Leblond, J.; Hubert-Buron, A.; Bole-Feysot, C.; Ducrotté, P.; Déchelotte, P.; Coëffier, M. Regulation of Proteolysis by Cytokines in the Human Intestinal Epithelial Cell Line HCT8: Role of IFNgamma. Biochimie 2006, 88 (7), 759-765.

(17) Kloetzel, P. M. Antigen Processing by the Proteasome. Nat. Rev. Mol. Cell Biol. 2001, 2 (3), 179-187.

(18) Inoue, S.; Nakase, H.; Matsuura, M.; Mikami, S.; Ueno, S.; Uza, N.; Chiba, T. The Effect of Proteasome Inhibitor MG132 on Experimental Inflammatory Bowel Disease. Clin. Exp. Immunol. 2009, $156(1), 172-182$.

(19) Schmidt, N.; Gonzalez, E.; Visekruna, A.; Kühl, A. A.; Loddenkemper, C.; Mollenkopf, H.; Kaufmann, S. H. E.; Steinhoff, U.; Joeris, T. Targeting the Proteasome: Partial Inhibition of the Proteasome by Bortezomib or Deletion of the Immunosubunit LMP7 Attenuates Experimental Colitis. Gut 2010, 59 (7), 896-906.

(20) Basler, M.; Dajee, M.; Moll, C.; Groettrup, M.; Kirk, C. J. Prevention of Experimental Colitis by a Selective Inhibitor of the Immunoproteasome. J. Immunol. Baltim. Md 1950 2010, 185 (1), 634-641. 
(21) Ghouzali, I.; Lemaitre, C.; Bahlouli, W.; Azhar, S.; Bôle-Feysot, C.; Meleine, M.; Ducrotté, P.; Déchelotte, P.; Coëffier, M. Targeting Immunoproteasome and Glutamine Supplementation Prevent Intestinal Hyperpermeability. Biochim. Biophys. Acta 2017, 1861 (1 Pt A), 3278-3288.

(22) Kilkenny, C.; Parsons, N.; Kadyszewski, E.; Festing, M. F. W.; Cuthill, I. C.; Fry, D.; Hutton, J.; Altman, D. G. Survey of the Quality of Experimental Design, Statistical Analysis and Reporting of Research Using Animals. PloS One 2009, 4 (11), e7824.

(23) Bradesi, S.; Schwetz, I.; Ennes, H. S.; Lamy, C. M. R.; Ohning, G.; Fanselow, M.; Pothoulakis, C.; McRoberts, J. A.; Mayer, E. A. Repeated Exposure to Water Avoidance Stress in Rats: A New Model for Sustained Visceral Hyperalgesia. Am. J. Physiol. Gastrointest. Liver Physiol. 2005, 289 (1), G42-53.

(24) Lee, J. Y.; Kim, N.; Kim, Y. S.; Nam, R. H.; Ham, M. H.; Lee, H. S.; Jo, W.; Shim, Y.; Choi, Y. J.; Yoon, H.; et al. Repeated Water Avoidance Stress Alters Mucosal Mast Cell Counts, Interleukin-1 $\beta$ Levels with Sex Differences in the Distal Colon of Wistar Rats. $J$. Neurogastroenterol. Motil. 2016, 22 (4), 694-704.

(25) Larauche, M.; Gourcerol, G.; Million, M.; Adelson, D. W.; Taché, Y. Repeated Psychological Stress-Induced Alterations of Visceral Sensitivity and Colonic Motor Functions in Mice: Influence of Surgery and Postoperative Single Housing on Visceromotor Responses. Stress Amst. Neth. 2010, 13 (4), 343-354.

(26) Jésus, P.; Ouelaa, W.; François, M.; Riachy, L.; Guérin, C.; Aziz, M.; Do Rego, J.-C.; Déchelotte, P.; Fetissov, S. O.; Coëffier, M. Alteration of Intestinal Barrier Function during Activity-Based Anorexia in Mice. Clin. Nutr. Edinb. Scotl. 2014, 33 (6), 10461053. 
(27) Coëffier, M.; Claeyssens, S.; Hecketsweiler, B.; Lavoinne, A.; Ducrotté, P.; Déchelotte, P. Enteral Glutamine Stimulates Protein Synthesis and Decreases Ubiquitin MRNA Level in Human Gut Mucosa. Am. J. Physiol. Gastrointest. Liver Physiol. 2003, 285 (2), G266273.

(28) Goichon, A.; Coëffier, M.; Claeyssens, S.; Lecleire, S.; Cailleux, A.-F.; Bôle-Feysot, C.; Chan, P.; Donnadieu, N.; Lerebours, E.; Lavoinne, A.; et al. Effects of an Enteral Glucose Supply on Protein Synthesis, Proteolytic Pathways, and Proteome in Human Duodenal Mucosa. Am. J. Clin. Nutr. 2011, 94 (3), 784-794.

(29) Bertrand, J.; Marion-Letellier, R.; Azhar, S.; Chan, P.; Legrand, R.; Goichon, A.; Ghouzali, I.; Aziz, M.; Vaudry, D.; Savoye, G.; et al. Glutamine Enema Regulates Colonic Ubiquitinated Proteins but Not Proteasome Activities during TNBS-Induced Colitis Leading to Increased Mitochondrial Activity. Proteomics 2015, 15 (13), 2198-2210.

(30) Goichon, A.; Bertrand, J.; Chan, P.; Lecleire, S.; Coquard, A.; Cailleux, A.-F.; Vaudry, D.; Déchelotte, P.; Coëffier, M. Enteral Delivery of Proteins Enhances the Expression of Proteins Involved in the Cytoskeleton and Protein Biosynthesis in Human Duodenal Mucosa. Am. J. Clin. Nutr. 2015, 102 (2), 359-367.

(31) Vizcaíno, J. A.; Csordas, A.; del-Toro, N.; Dianes, J. A.; Griss, J.; Lavidas, I.; Mayer, G.; Perez-Riverol, Y.; Reisinger, F.; Ternent, T.; et al. 2016 Update of the PRIDE Database and Its Related Tools. Nucleic Acids Res. 2016, 44 (D1), D447-456.

(32) Huang, D. W.; Sherman, B. T.; Lempicki, R. A. Systematic and Integrative Analysis of Large Gene Lists Using DAVID Bioinformatics Resources. Nat. Protoc. 2009, 4 (1), 44 57. 
(33) Bertrand, J.; Tennoune, N.; Marion-Letellier, R.; Goichon, A.; Chan, P.; Mbodji, K.; Vaudry, D.; Déchelotte, P.; Coëffier, M. Evaluation of Ubiquitinated Proteins by Proteomics Reveals the Role of the Ubiquitin Proteasome System in the Regulation of Grp75 and Grp78 Chaperone Proteins during Intestinal Inflammation. Proteomics 2013, 13 (22), 3284-3292.

(34) Visekruna, A.; Joeris, T.; Schmidt, N.; Lawrenz, M.; Ritz, J.-P.; Buhr, H. J.; Steinhoff, U. Comparative Expression Analysis and Characterization of 20S Proteasomes in Human Intestinal Tissues: The Proteasome Pattern as Diagnostic Tool for IBD Patients. Inflamm. Bowel Dis. 2009, 15 (4), 526-533.

(35) Rolland-Fourcade, C.; Denadai-Souza, A.; Cirillo, C.; Lopez, C.; Jaramillo, J. O.; Desormeaux, C.; Cenac, N.; Motta, J.-P.; Larauche, M.; Taché, Y.; et al. Epithelial Expression and Function of Trypsin-3 in Irritable Bowel Syndrome. Gut 2017, 66 (10), $1767-1778$.

(36) Moloney, R. D.; O’Mahony, S. M.; Dinan, T. G.; Cryan, J. F. Stress-Induced Visceral Pain: Toward Animal Models of Irritable-Bowel Syndrome and Associated Comorbidities. Front. Psychiatry 2015, 6, 15.

(37) Seifert, U.; Bialy, L. P.; Ebstein, F.; Bech-Otschir, D.; Voigt, A.; Schröter, F.; Prozorovski, T.; Lange, N.; Steffen, J.; Rieger, M.; et al. Immunoproteasomes Preserve Protein Homeostasis upon Interferon-Induced Oxidative Stress. Cell 2010, 142 (4), 613624.

(38) Nathan, J. A.; Spinnenhirn, V.; Schmidtke, G.; Basler, M.; Groettrup, M.; Goldberg, A. L. Immuno- and Constitutive Proteasomes Do Not Differ in Their Abilities to Degrade Ubiquitinated Proteins. Cell 2013, 152 (5), 1184-1194. 
(39) Setsuie, R.; Suzuki, M.; Tsuchiya, Y.; Wada, K. Skeletal Muscles of Uchl3 Knockout Mice Show Polyubiquitinated Protein Accumulation and Stress Responses. Neurochem. Int. 2010, 56 (8), 911-918.

(40) Kim, J. Y.; Lee, J.-M.; Cho, J.-Y. Ubiquitin C-Terminal Hydrolase-L3 Regulates Smad1 Ubiquitination and Osteoblast Differentiation. FEBS Lett. 2011, 585 (8), 1121-1126.

(41) Sano, Y.; Furuta, A.; Setsuie, R.; Kikuchi, H.; Wang, Y.-L.; Sakurai, M.; Kwon, J.; Noda, M.; Wada, K. Photoreceptor Cell Apoptosis in the Retinal Degeneration of Uchl3Deficient Mice. Am. J. Pathol. 2006, 169 (1), 132-141.

(42) Song, H. M.; Lee, J. E.; Kim, J. H. Ubiquitin C-Terminal Hydrolase-L3 Regulates EMT Process and Cancer Metastasis in Prostate Cell Lines. Biochem. Biophys. Res. Commun. 2014, 452 (3), 722-727.

(43) Rolén, U.; Kobzeva, V.; Gasparjan, N.; Ovaa, H.; Winberg, G.; Kisseljov, F.; Masucci, M. G. Activity Profiling of Deubiquitinating Enzymes in Cervical Carcinoma Biopsies and Cell Lines. Mol. Carcinog. 2006, 45 (4), 260-269.

(44) Miyoshi, Y.; Nakayama, S.; Torikoshi, Y.; Tanaka, S.; Ishihara, H.; Taguchi, T.; Tamaki, Y.; Noguchi, S. High Expression of Ubiquitin Carboxy-Terminal Hydrolase-L1 and -L3 MRNA Predicts Early Recurrence in Patients with Invasive Breast Cancer. Cancer Sci. 2006, 97 (6), 523-529.

(45) Zhao, P.; Guo, T.; Qian, L.; Wang, X.; Yuan, Y.; Cheng, Q.; Zuo, Y.; Liu, J.; Miao, Y.; Feng, Q.; et al. Ubiquitin C-Terminal Hydrolase-L3 Promotes Interferon Antiviral Activity by Stabilizing Type I-Interferon Receptor. Antiviral Res. 2017, 144, 120-129.

(46) Kanarek, N.; Ben-Neriah, Y. Regulation of NF-KB by Ubiquitination and Degradation of the IкBs. Immunol. Rev. 2012, 246 (1), 77-94. 
(47) Coëffier, M.; Marion-Letellier, R.; Déchelotte, P. Potential for Amino Acids Supplementation during Inflammatory Bowel Diseases. Inflamm. Bowel Dis. 2010, 16 (3), $518-524$.

(48) Singleton, K. D.; Wischmeyer, P. E. Glutamine Attenuates Inflammation and NF-KappaB Activation via Cullin-1 Deneddylation. Biochem. Biophys. Res. Commun. 2008, 373 (3), $445-449$.

(49) Beutheu, S.; Ouelaa, W.; Guérin, C.; Belmonte, L.; Aziz, M.; Tennoune, N.; Bôle-Feysot, C.; Galas, L.; Déchelotte, P.; Coëffier, M. Glutamine Supplementation, but Not Combined Glutamine and Arginine Supplementation, Improves Gut Barrier Function during Chemotherapy-Induced Intestinal Mucositis in Rats. Clin. Nutr. Edinb. Scotl. 2014, 33 (4), 694-701.

(50) Beutheu, S.; Ghouzali, I.; Galas, L.; Déchelotte, P.; Coëffier, M. Glutamine and Arginine Improve Permeability and Tight Junction Protein Expression in Methotrexate-Treated Caco-2 Cells. Clin. Nutr. Edinb. Scotl. 2013, 32 (5), 863-869.

(51) Choi, K.; Lee, S. S.; Oh, S. J.; Lim, S. Y.; Lim, S. Y.; Jeon, W. K.; Oh, T. Y.; Kim, J. W. The Effect of Oral Glutamine on 5-Fluorouracil/Leucovorin-Induced Mucositis/Stomatitis Assessed by Intestinal Permeability Test. Clin. Nutr. Edinb. Scotl. 2007, 26 (1), 57-62.

(52) Daniele, B.; Perrone, F.; Gallo, C.; Pignata, S.; De Martino, S.; De Vivo, R.; Barletta, E.; Tambaro, R.; Abbiati, R.; D'Agostino, L. Oral Glutamine in the Prevention of Fluorouracil Induced Intestinal Toxicity: A Double Blind, Placebo Controlled, Randomised Trial. Gut 2001, 48 (1), 28-33. 
(53) Hubert-Buron, A.; Leblond, J.; Jacquot, A.; Ducrotté, P.; Déchelotte, P.; Coëffier, M. Glutamine Pretreatment Reduces IL-8 Production in Human Intestinal Epithelial Cells by Limiting IkappaBalpha Ubiquitination. J. Nutr. 2006, 136 (6), 1461-1465.

(54) Bertrand, J.; Ghouzali, I.; Guérin, C.; Bôle-Feysot, C.; Gouteux, M.; Déchelotte, P.; Ducrotté, P.; Coëffier, M. Glutamine Restores Tight Junction Protein Claudin-1 Expression in Colonic Mucosa of Patients With Diarrhea-Predominant Irritable Bowel Syndrome. JPEN J. Parenter. Enteral Nutr. 2016, 40 (8), 1170-1176.

(55) Zhou, Q.; Costinean, S.; Croce, C. M.; Brasier, A. R.; Merwat, S.; Larson, S. A.; Basra, S.; Verne, G. N. MicroRNA 29 Targets Nuclear Factor-KB-Repressing Factor and Claudin 1 to Increase Intestinal Permeability. Gastroenterology 2015, 148 (1), 158-169.e8.

(56) Zhou, Q.; Verne, M. L.; Fields, J. Z.; Lefante, J. J.; Basra, S.; Salameh, H.; Verne, G. N. Randomised Placebo-Controlled Trial of Dietary Glutamine Supplements for Postinfectious Irritable Bowel Syndrome. Gut 2018.

(57) Li, N.; Neu, J. Glutamine Deprivation Alters Intestinal Tight Junctions via a PI3-K/Akt Mediated Pathway in Caco-2 Cells. J. Nutr. 2009, 139 (4), 710-714.

(58) Coëffier, M.; Déchelotte, P.; Ducrotté, P. Intestinal Permeability in Patients with DiarrheaPredominant Irritable Bowel Syndrome: Is There a Place for Glutamine Supplementation? Gastroenterology 2015, 148 (5), 1079-1080.

(59) Zhou, Q.; Verne, G. N. Reply: To PMID 25277410. Gastroenterology 2015, 148 (5), $1080-1081$.

(60) Cleynen, I.; Vazeille, E.; Artieda, M.; Verspaget, H. W.; Szczypiorska, M.; Bringer, M.A.; Lakatos, P. L.; Seibold, F.; Parnell, K.; Weersma, R. K.; et al. Genetic and Microbial 
Factors Modulating the Ubiquitin Proteasome System in Inflammatory Bowel Disease. Gut 2014, 63 (8), 1265-1274. 


\section{FIGURE LEGENDS:}

Figure 1. Colonic proteome alterations in wild-type (wt) and $\beta 2 \mathrm{i}^{-/-}$mice during WAS

(A) Silver-stained 2-dimensional gel images representing colonic proteome from wt control $(\mathrm{Ct})$, $\beta 2 \mathrm{i}^{--} \mathrm{Ct}$, wt WAS and $\beta 2 \mathrm{i}^{---}$WAS mice. For isoelectric focusing, $40 \mu \mathrm{g}$ of total colonic proteins was separated onto pH 3-10 NL IPG strip (18 cm). SDS-PAGE was performed 4-16\% gel and proteins were revealed with silver staining. The molecular weight of each protein was determined by standard markers. Differentially expressed proteins ( $>1.4$ fold difference; circled spots with a number) were determined by statistical analysis (two-way ANOVA, $P<0.05$ ). Protein spots identification is displayed in Table 1. (B) Pie chart depicting the functional classification of proteins differentially expressed between the four groups mice. Using the online resource PANTHER classification system, proteins of interest were categorized into the broad GO classes biological process and molecular function. For each category, the number of identified proteins and their percentage of the total number of proteins in the pie chart are indicated for each GO term.

Figure 2. Expression levels of GDH1, HSP60, UCH-L3 and ubiquitinated proteins in the colonic mucosa of $\beta 2 \mathrm{i}^{-/-}$WAS mice

Representative immunoblots and densitometric analysis of GDH-1 (A), HSP60 (A), UCH-L3 (A), ubiquitinated protein (B) and $\beta$-actin levels in the colonic mucosa of wild-type (wt) or $\beta 2 \mathrm{i}$ knock-out $\left(\beta 2 \mathrm{i}^{--}\right)$mice subjected to WAS (1 h/day for 10 days) or not (Control; Ct). Values are means \pm sem ( $\mathrm{n}=5$ per group). Open and closed bars represent control and WAS mice, respectively. Two-way ANOVA $P$ values: (A. GDH1) $P($ WAS $)=0.0363, P\left(\beta 2 \mathrm{i}^{-/-}\right)=0.0305$, 
$\mathrm{p}($ interaction $)=0.1709 ;($ A. HSP60 $) P($ WAS $)=0.0013, P\left(\beta 2 \mathrm{i}^{-/-}\right)=0.0388, P($ interaction $)=$ 0.0805; (A. UCH-L3) $P($ WAS $)=0.1797, P\left(\beta 2 \mathrm{i}^{--}\right)=0.0019, P($ interaction $)=0.9172 ;(\mathrm{B})$ $P($ WAS $)<0.0001, P\left(\beta 2 \mathrm{i}^{---}\right)=0.0243, P($ interaction $)=0.1393 .{ }^{*}, P<0.05$ vs. wt Ct; $\#, P<0.05$ vs. wt WAS; and $\$, P<0.05$ vs. $\beta 2 \mathrm{i}^{-/-}$Ct. GDH-1, Glutamate dehydrogenase 1 ; HSP60, $60 \mathrm{kDa}$ heat shock protein; UCH-L3, Ubiquitin carboxyl-terminal hydrolase isozyme L3.

Figure 3. Schema of mitochondrial and energy metabolism alterations in the colonic mucosa WAS induces protein expression changes in the colon tissue of wt mice (in red) and $\beta 2 \mathrm{i}^{-}$ I- mice (in mauve). These changes are different from those induced by $\beta 2 \mathrm{i}$ subunit deficiency during WAS (in green). Proteins in red, mauve or green are downregulated in the colonic mucosa of mice, excepted for UPase 1: Adss2, Adenylosuccinate synthetase isozyme 2; AK, Adenosine kinase; Atp5b, ATP synthase subunit beta; EF-G1mt, Elongation factor G1; EF-G2mt, Elongation factor G2; ENO1, alpha-enolase 1; GDH1, Glutamate dehydrogenase 1 ; HSP60, 60 kDa heat shock protein; HSP75, Heat shock protein 75; IVD, isovaleryl-CoA dehydrogenase; Mic60, MICOS complex subunit; MST, 3-mercaptopyruvate sulfurtransferase; PKM, Pyruvate kinase; Vsp4b, Vacuolar protein sorting-associating protein 4B. These modifications suggest a significant decrease of mitochondrial activity and energy metabolism in the colonic mucosa of wt mice during WAS. Interestingly, these metabolic disturbances were minored in $\beta 2 \mathrm{i}^{-{ }^{-}}$WAS mice.

\section{Figure 4. Schema of ubiquitin-proteasome system (UPS) alterations in the colonic mucosa}

WAS induces protein expression changes in the colon tissue of wt mice (in red) and $\beta 2 \mathrm{i}^{-{ }_{-}}$mice (in mauve). These changes are different from those induced by $\beta 2 \mathrm{i}$ subunit deficiency during 
WAS (in green). The external and internal rings constitute the $20 \mathrm{~S}$ proteasome. The lid and base constitute the $19 \mathrm{~S}$ regulatory complex. In some cases, it can be replaced by the PA28 or $11 \mathrm{~S}$ regulatory complex, constituted of a single ring of 7 subunits. Proteins in red, mauve or green are upregulated (plus sign, +) or downregulated (minus sign, -) in the colonic mucosa of mice: DJ-1, Protein deglycase; Prp19, Pre-mRNA-processing factor 19; PSMA3, Proteasome subunit alpha type-3; PSMA4, Proteasome subunit alpha type-4; PSMA5, Proteasome subunit alpha type-5; PSMC6, 26S protease regulatory subunit S10B; UCH-L3, Ubiquitin carboxyl-terminal hydrolase isozyme L3. These modifications suggest altered UPS function in the colonic mucosa of wt mice during WAS. It was also observed disturbances in UPS in $\beta 2 \mathrm{i}^{--}$WAS mice. In this case, immunoproteasome subunit beta2i deficiency induces increased colonic expression of UCH-L3, PSMA3 and PSMA5 in stressed mice, while PSMA4 were downregulated. $\alpha$, proteasome alpha subunit; $\beta$, proteasome beta subunit, DUBs, deubiquitinating enzymes; E1, ubiquitin-activating enzyme; E2, ubiquitin-conjugating enzyme; E3, ubiquitin ligase; Ub, Ubiquitin.

Figure 5. Expression of ubiquitinated proteins in the colonic mucosa of IBS-D patients. The ubiquitinated forms (Ub) of A20, COX-2, HSP70, HSP90, IRF3, Nrf2 and TRAF6 are underexpressed in the colonic mucosa of IBS-D patients

Representative macroarray results (A) and densitometric analysis (B) of ubiquitinated protein expression in the colonic mucosa of IBS-D or control patients. $300 \mu \mathrm{g}$ of colonic mucosal proteins from IBS-D or control patients were incubated with a Human ubiquitin macroarray $(\mathrm{n}=$ 7-8 per group). A ratio of signal intensity "R" (IBS-D / control) was calculated, and log transformed (base2). Significant changes $\left(\log _{2} \mathrm{R}<-0.584\right.$ or $\log _{2} \mathrm{R}>0.584$; Mann-Whitney test, $P<0.05)$ are showed by black bars. A20, Tumor necrosis factor alpha-induced protein 3; 
COX-2, Prostaglandin G/H synthase 2; HSP70, Heat shock 70 kDa protein; HSP90, Heat shock protein HSP 90; IRF3, Interferon regulatory factor 3; Nrf2, Nuclear factor erythroid 2-related factor 2; TRAF-6, TNF receptor-associated factor 6; Ub, Ubiquitin.

Figure 6. Speculative schema of interactions between UCH-L3, glutamine content and inflammatory response in the colonic mucosa of immunoproteasome-deficient stressed mice In wild-type mice, stress induces the neddylation of cullin-1 that is necessary for activation of the ubiquitin ligase E3 complex, SCF- ${ }^{\beta-\operatorname{TrCP}}$. Active SCF- ${ }^{\beta-\operatorname{TrCP}}$ induces ubiquitination of $\mathrm{I}-\mathrm{kB}$, the inhibitor of NF- $\kappa B$, leading to the degradation of I- $\kappa B$, the translocation of NF-kB in the nucleus and transcription of NF-kB-dependent genes. In immunoproteasome deficient mice, the expression of deubiquitinase (UCH-L3) is increased, while the expression of glutamate dehydrogenase 1 (GDH1) is decreased. Underexpression of GDH1 may lead to higher glutamine content. Both UCH-L3 and glutamine are able to inhibit cullin-1 neddylation. Consequently, I$\kappa \mathrm{B}$ is not degraded by proteasome and NF- $\mathrm{B}$ remains in the cytosol leading to the limitation of inflammatory response. 
Figure 1.

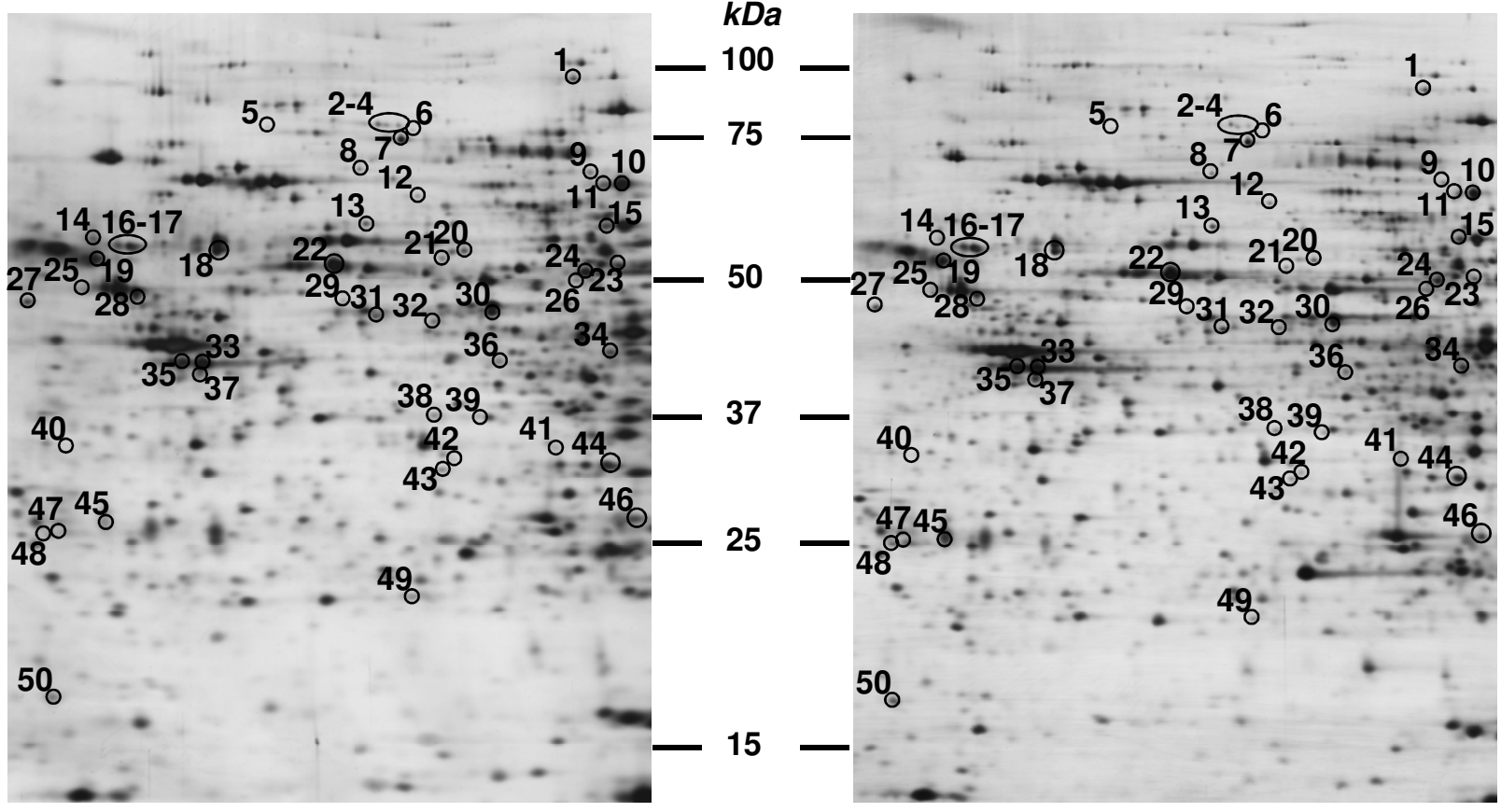

wt WAS

$\beta 2 i^{-/-}$WAS

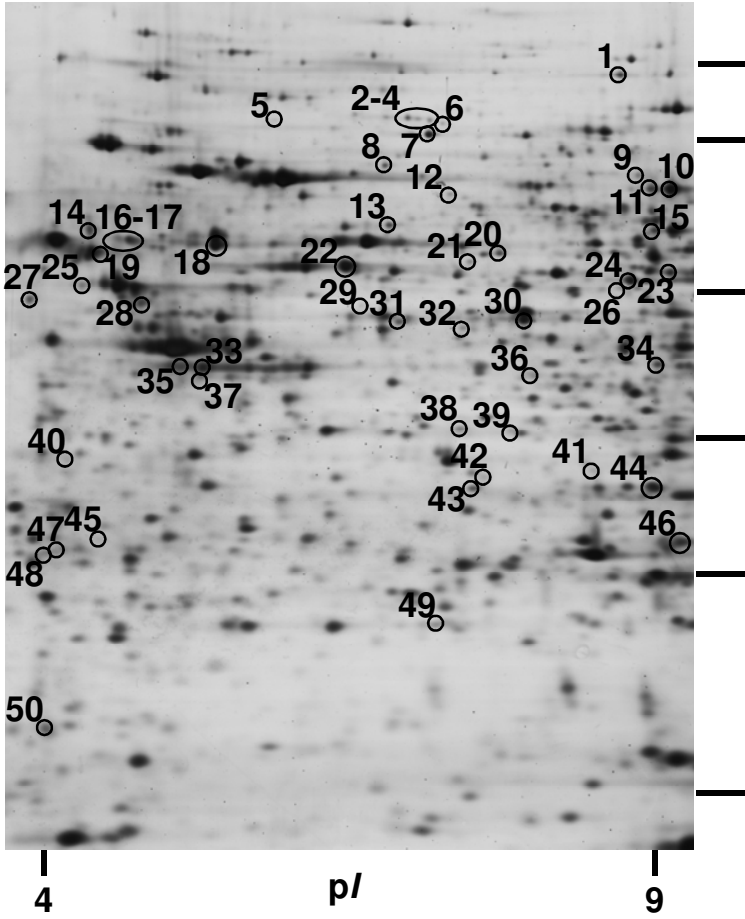

Biological process

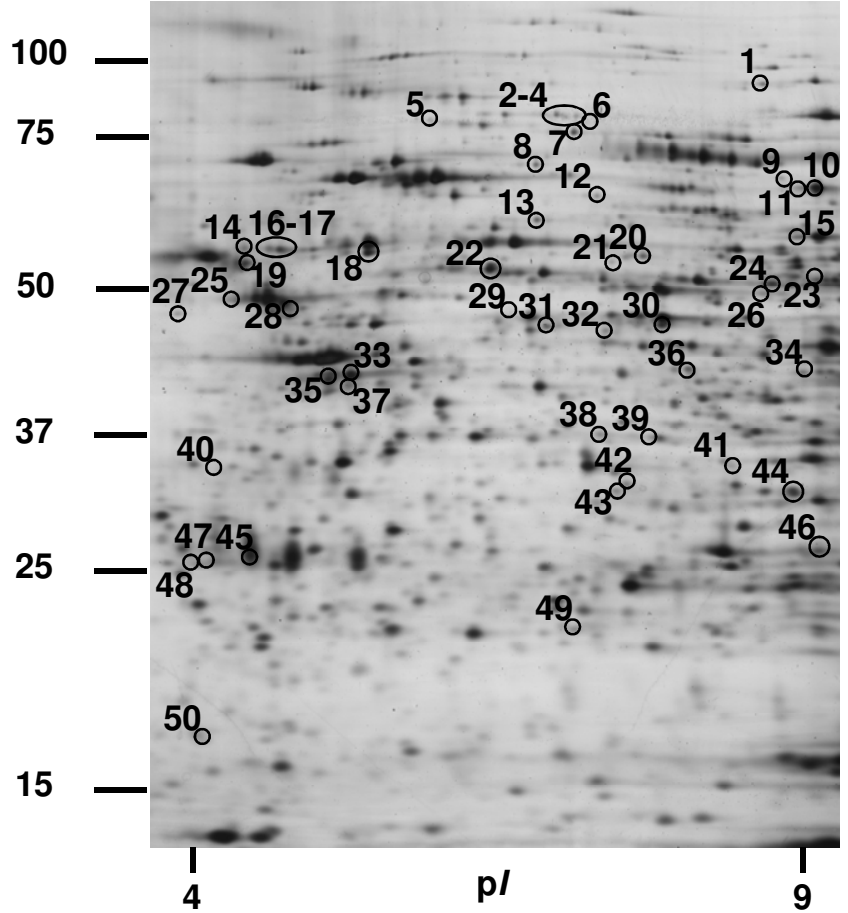

B

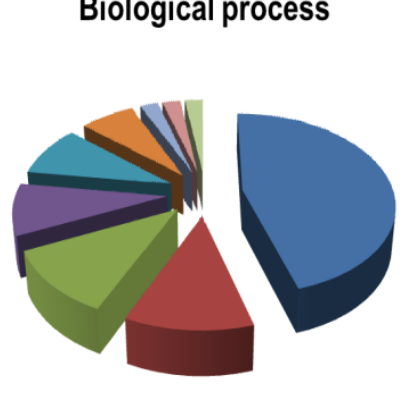

Metabolic process $(20 ; 45.5 \%)$

- Biological regulation $(5 ; 11.4 \%)$

- Response to stimulus $(5 ; 11.4 \%)$

- Cellular process $(4 ; 9.1 \%)$

n Developmental process $(4 ; 9.1 \%)$

- Localization ( $3 ; 6.8 \%)$

- Cellular component organization (1;2.3\%)

Apoptotic process $(1 ; 2.3 \%)$

Molecular function

Multicellular organismal process (1; $2.3 \%$ )

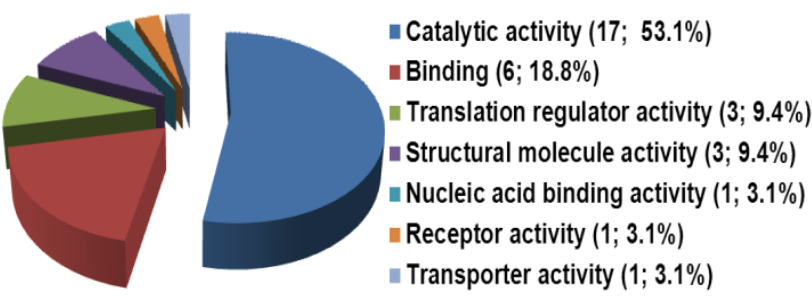


Figure 2.

A
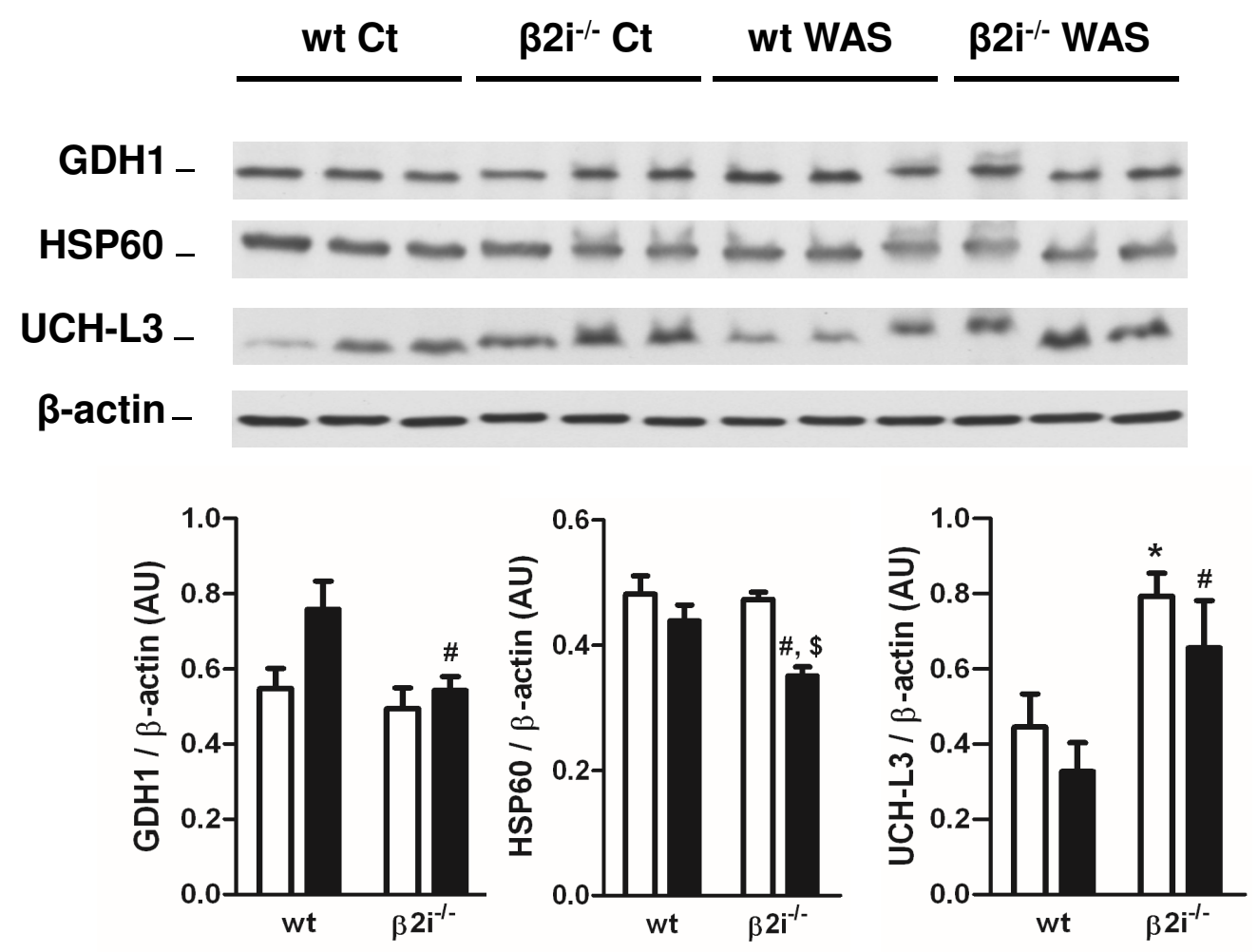

B

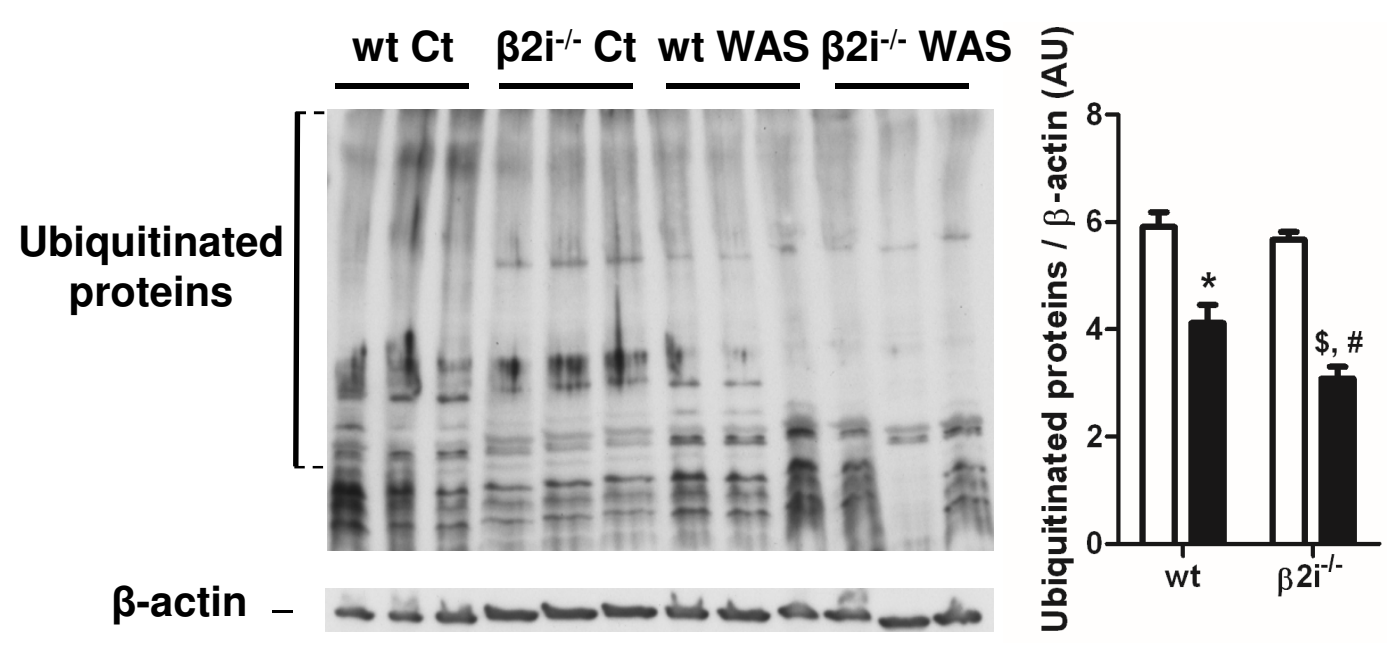




\section{Figure 3.}

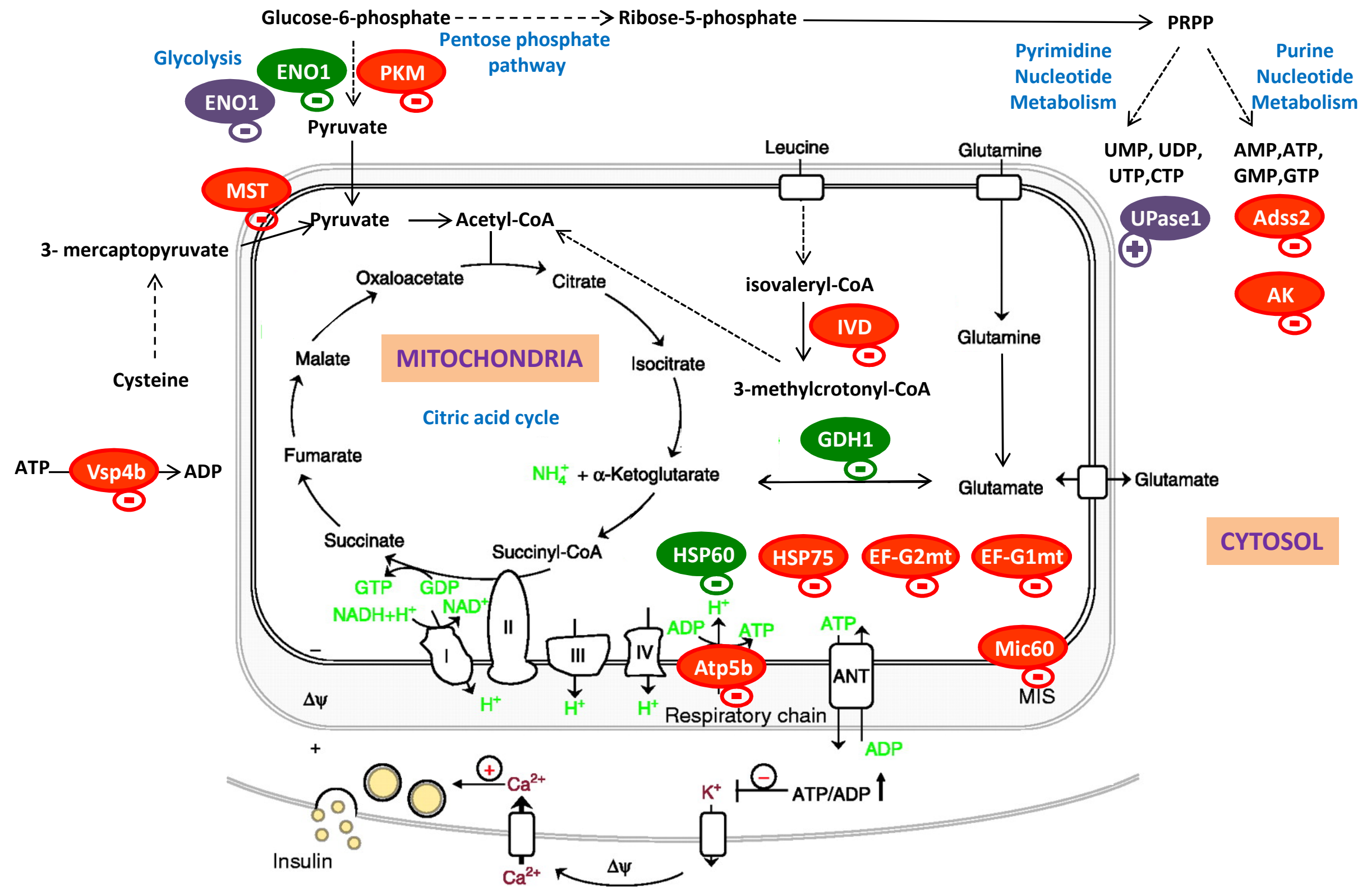


Figure 4.

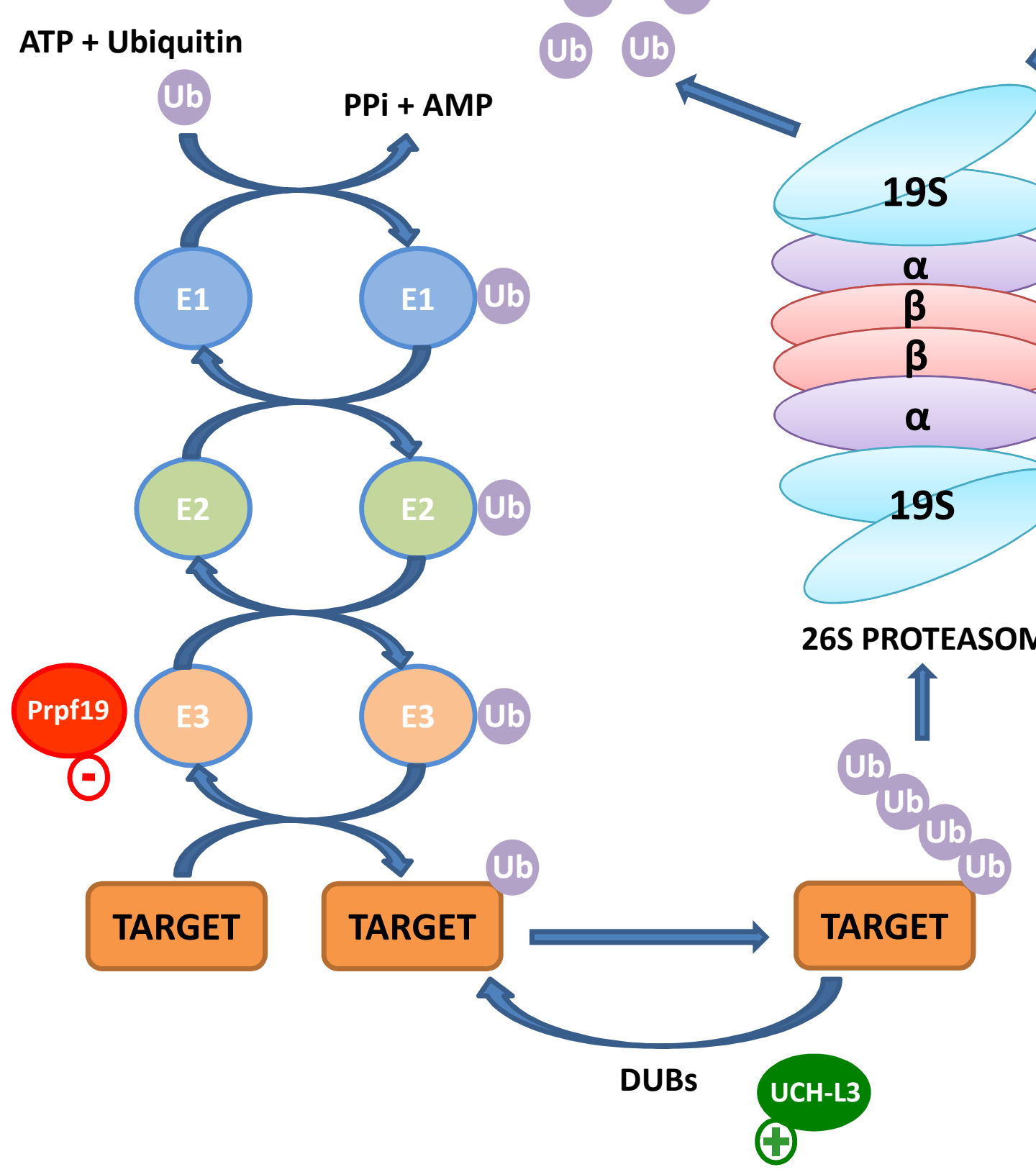




\section{Figure 5.}

A

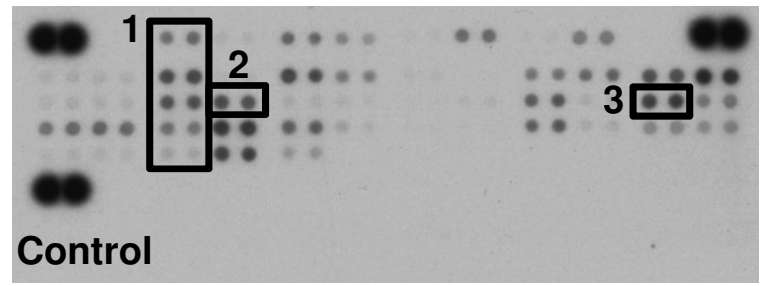

1
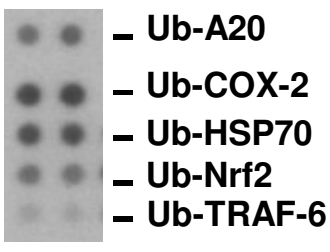

3

\section{IBS-D}

1

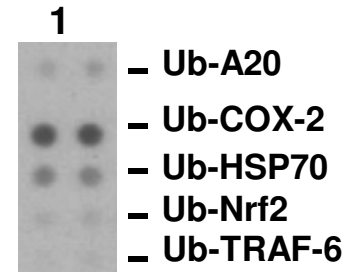

2

3
2

- Ub-HSP90

3

- Ub-IRF3

- Ub-HSP90

- Ub-IRF3

B

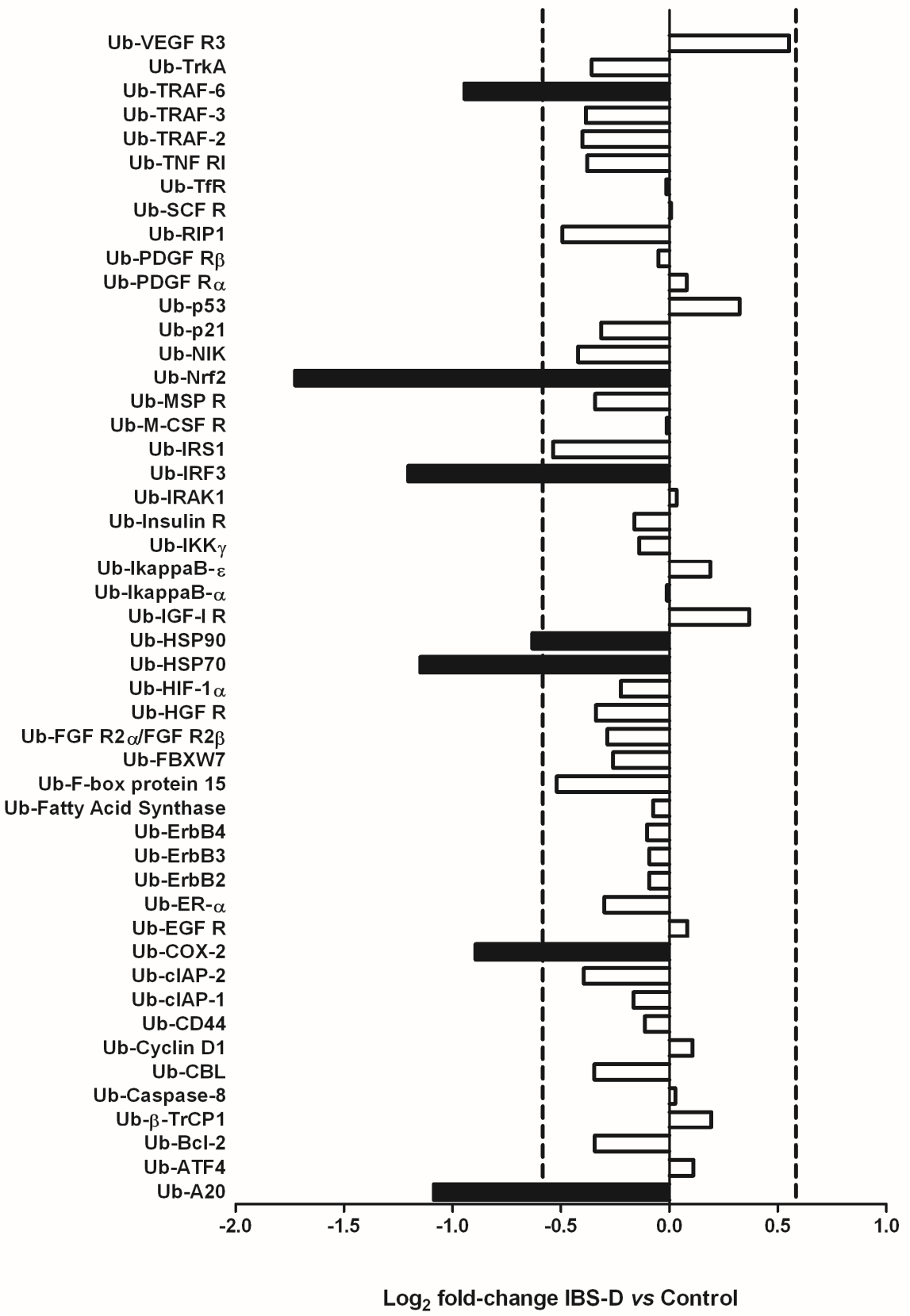


Figure 6.

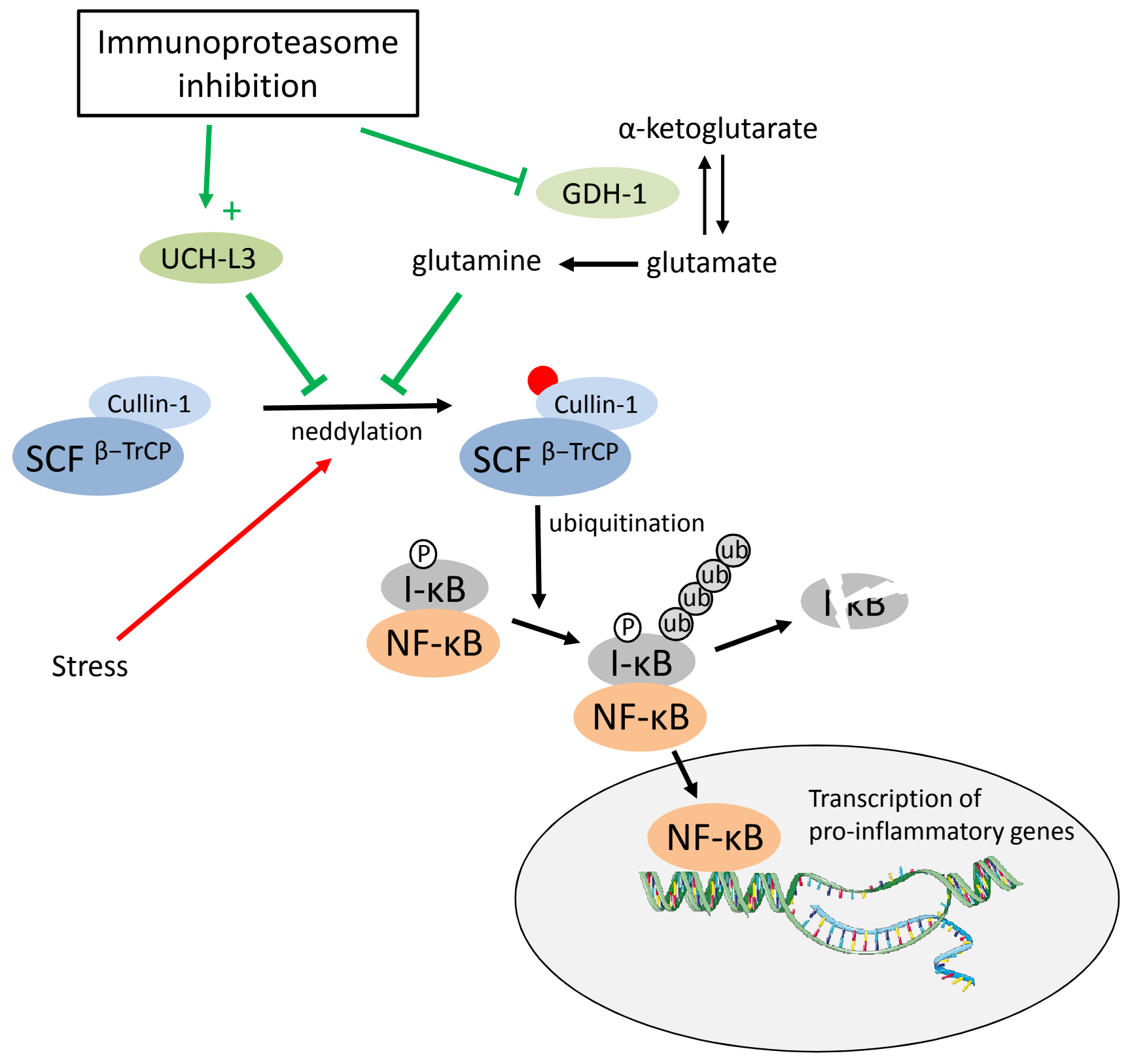


Table 1. Colonic protein expression changes in wild-type $(\mathrm{wt})$ and $\beta 2 \mathrm{i}$ immunoproteasome subunit knock-out $\left(\beta 2 \mathrm{i}^{-{ }^{-}}\right)$mice during water

\section{avoidance stress (WAS) or no stress $(\mathrm{Ct})$}

\begin{tabular}{|c|c|c|c|c|c|c|c|c|c|c|}
\hline \multirow{2}{*}{$\begin{array}{c}\text { Spot } \\
\text { number }\end{array}$} & \multirow{2}{*}{$\begin{array}{c}\text { Swiss-Prot } \\
\text { accession } \\
\text { number }\end{array}$} & \multirow[b]{2}{*}{ Protein name (short name) } & \multicolumn{2}{|c|}{ Theoretical $^{\mathbf{a}}$} & \multirow{2}{*}{ 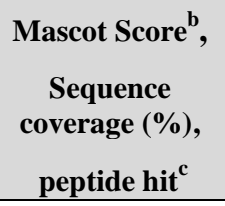 } & \multicolumn{4}{|c|}{ Fold change $^{d}$} & \multirow{2}{*}{$\begin{array}{l}\text { Two-way ANOVA: } \\
P(\text { WAS }), P\left(\beta 2 \mathrm{i}^{-{ }^{-}}\right) \\
P(\text { interaction })\end{array}$} \\
\hline & & & $\mathbf{p} I$ & $\begin{array}{c}M \mathbf{r} \\
(\mathbf{k D a})\end{array}$ & & $\begin{array}{c}\text { wt Ct/ } \\
\text { wt WAS }\end{array}$ & $\begin{array}{c}\text { wt Ct/ } \\
\beta 2 \mathrm{i}^{-/-} \mathbf{C t}\end{array}$ & $\begin{array}{c}\boldsymbol{\beta 2 \mathrm { i } ^ { - / - }} \mathbf{C t} / \\
\boldsymbol{\beta} \mathbf{i}^{-/-} \text {WAS }\end{array}$ & $\begin{array}{c}\text { wt WAS / } \\
\boldsymbol{\beta 2 i}^{-i^{--}} \text {WAS }\end{array}$ & \\
\hline 1 & P58252 & Elongation factor 2 (EF-2) & 6.41 & 95.3 & $94.0,4 \%, 4$ & -3.23 & -3.74 & NS & NS & $0.0553,0.0345,0.0786$ \\
\hline 2 & Q8CAQ8 & MICOS complex subunit Mic60 (IMMT) & 6.18 & 83.8 & $166,9 \%, 6$ & -1.41 & -1.46 & NS & NS & $0.0498,0.0134,0.1482$ \\
\hline 3 & Q8K0D5 & Elongation factor G1 (EF-G1mt) & 6.48 & 83.5 & $76.0,6 \%, 4$ & -1.88 & -2.17 & NS & NS & $0.0699,0.0179,0.0180$ \\
\hline 4 & Q8CAQ8 & MICOS complex subunit Mic60 (IMMT) & 6.18 & 83.8 & $147,8 \%, 4$ & -1.60 & -1.52 & NS & NS & $0.0576,0.1305,0.0072$ \\
\hline 5 & Q8R2Q4 & Elongation factor G2 (EF-G2mt) & 5.98 & 85.9 & $63.0,3 \%, 2$ & -1.74 & -1.98 & NS & NS & $0.2957,0.0986,0.0095$ \\
\hline 6 & Q9WU78 & Programmed cell death 6-interacting protein (Pdcd6ip) & 6.15 & 96.0 & $121,7 \%, 5$ & -2.48 & -2.14 & NS & NS & $0.0145,0.0446,0.0222$ \\
\hline 7 & P26040 & Ezrin (Ezr) & 5.83 & 69.4 & $267,9 \%, 6$ & -1.53 & -1.93 & NS & NS & $0.0345,0.0019,0.2013$ \\
\hline 8 & Q9CQN1 & Heat shock protein $75 \mathrm{kDa}$ (HSP75) & 6.25 & 80.2 & $90.0,8 \%, 4$ & -1.51 & -1.63 & NS & NS & $0.2076,0.0898,0.0375$ \\
\hline 9 & - & Undetermined & - & - & - & -2.23 & -1.84 & NS & NS & $0.0002,0.0047,0.0028$ \\
\hline 10 & - & Undetermined & - & - & - & -1.42 & -1.59 & NS & NS & $0.0391,0.0062,0.1552$ \\
\hline 11 & - & Undetermined & - & - & - & -1.58 & -1.77 & NS & NS & $0.0244,0.0056,0.1831$ \\
\hline 12 & - & Undetermined & - & - & - & -1.48 & -1.71 & NS & NS & $0.2286,0.0269,0.0112$ \\
\hline 13 & P11984 & T-complex protein 1 subunit alpha A (TCP-1-A) & 5.76 & 60.3 & $203,11 \%, 5$ & -1.89 & -1.79 & NS & NS & $0.0074,0.0146,0.0528$ \\
\hline 14 & P09103 & Protein disulfide-isomerase precursor (PDI) & 4.79 & 57.1 & $151.0,7 \%, 4$ & -2.36 & -2.81 & NS & NS & $0.0056,0.0010,0.0018$ \\
\hline 15 & P52480 & Pyruvate kinase (PKM) & 7.18 & 57.8 & $300,24 \%, 11$ & -1.73 & -1.77 & NS & NS & $0.0358,0.0277,0.0206$ \\
\hline 16 & P09103 & Protein disulfide-isomerase precursor (PDI) & 4.79 & 57.1 & $201,10 \%, 5$ & -2.89 & -1.70 & NS & NS & $0.0097,0.4592,0.0099$ \\
\hline 17 & P09103 & Protein disulfide-isomerase precursor (PDI) & 4.79 & 57.1 & $174,14 \%, 6$ & -2.59 & -1.89 & NS & NS & $0.0135,0.2347,0.0015$ \\
\hline 18 & P63038 & $60 \mathrm{kDa}$ heat shock protein (HSP60) & 5.90 & 60.9 & $821,28 \%, 13$ & NS & NS & NS & -1.86 & $0.0399,0.0014,0.4110$ \\
\hline 19 & P99024 & Tubulin beta- 5 chain (Tubb5) & 4.78 & 49.6 & $552,24 \%, 9$ & -1.83 & -1.85 & NS & NS & $0.0020,0.0017,0.0532$ \\
\hline 20 & Q99KP6 & Pre-mRNA-processing factor 19 (Prpf19) & 6.14 & 55.2 & $169,10 \%, 3$ & -1.48 & 1.72 & NS & NS & $0.0325,0.0021,0.0463$ \\
\hline 21 & P46467 & Vacuolar protein sorting-associating protein 4B (Vps4b) & 6.65 & 49.4 & $79.0,7 \%, 3$ & -1.68 & NS & NS & NS & $0.0276,0.2884,0.1122$ \\
\hline 22 & - & Undetermined & - & - & & -2.78 & -2.85 & NS & NS & $0.0171,0.0145,0.0136$ \\
\hline 23 & Q91ZJ5 & UTP--glucose-1-phosphate uridylyltransferase (Ugp2) & 7.18 & 57.0 & $216,17 \%, 6$ & -1.60 & -1.61 & NS & NS & $0.0059,0.0055,0.4087$ \\
\hline 24 & P26443 & Glutamate dehydrogenase 1 (GDH1) & 8.05 & 61.3 & $393,31 \%, 13$ & NS & NS & NS & -1.48 & $0.0201,0.0041,0.7822$ \\
\hline 25 & P56480 & ATP synthase subunit beta (Atp5b) & 5.19 & 56.3 & $294,21 \%, 7$ & -1.63 & NS & NS & NS & $0.0023,0.9397,0.4053$ \\
\hline
\end{tabular}


Table 1. (Continued)

\begin{tabular}{|c|c|c|c|c|c|c|c|c|c|c|}
\hline \multirow{2}{*}{$\begin{array}{c}\text { Spot } \\
\text { number }\end{array}$} & \multirow{2}{*}{$\begin{array}{c}\text { Swiss-Prot } \\
\text { accession } \\
\text { number }\end{array}$} & \multirow[b]{2}{*}{ Protein name (short name) } & \multicolumn{2}{|c|}{ Theoretical $^{\mathrm{a}}$} & \multirow{2}{*}{$\begin{array}{c}\text { Mascot Score }^{\mathrm{b}} \\
\text { Sequence } \\
\text { coverage }(\%) \\
\text { peptide hit }^{\mathrm{c}}\end{array}$} & \multicolumn{4}{|c|}{ Fold change $^{d}$} & \multirow{2}{*}{$\begin{array}{c}\text { Two-way ANOVA: } \\
P(\text { WAS }), P\left(\beta 2 i^{-/-}\right) \\
P(\text { interaction })\end{array}$} \\
\hline & & & $\mathbf{p} I$ & $\begin{array}{c}M \mathbf{r} \\
(\mathbf{k D a})\end{array}$ & & $\begin{array}{c}\text { wt } \mathrm{Ct} / \\
\text { wt WAS }\end{array}$ & $\begin{array}{c}\text { wt Ct/ } \\
\beta 2 i^{-/-} \mathbf{C t}\end{array}$ & $\begin{array}{c}\boldsymbol{\beta 2 \mathbf { i } ^ { - / }} \mathbf{C t} / \\
\boldsymbol{\beta 2 \mathbf { i } ^ { - / - }} \text { WAS }\end{array}$ & $\begin{array}{c}\text { wt WAS / } \\
\beta 2 \mathrm{i}^{-I_{-}} \text {WAS }\end{array}$ & \\
\hline 26 & - & Undetermined & - & - & - & NS & NS & +1.59 & +1.67 & $0.0277,0.0127,0.0312$ \\
\hline 27 & - & Undetermined & - & - & - & -2.01 & -1.70 & NS & NS & $0.0015,0.0159,0.0318$ \\
\hline 28 & - & Undetermined & - & - & - & NS & -1.60 & NS & NS & $0.249,0.0452,0.03630$ \\
\hline 29 & - & Undetermined & - & - & - & -1.65 & -1.83 & NS & NS & $0.080,0.0286,0.11610$ \\
\hline 30 & P17182 & Alpha-enolase 1 (Eno1) & 6.37 & 47.1 & $773,26 \%, 9$ & NS & NS & -1.55 & -1.65 & $0.030,0.0078,0.13510$ \\
\hline 31 & P55264 & Adenosine kinase (AK) & 5.84 & 40.1 & $162,16 \%, 5$ & -1.76 & NS & NS & NS & $0.0188,0.1506,0.2865$ \\
\hline 32 & P46664 & Adenylosuccinate synthetase isozyme $2($ Adss2) & 5.98 & 50.0 & $111.0,7 \%, 3$ & -1.45 & -1.55 & NS & NS & $0.1908,0.0202,0.0465$ \\
\hline 33 & - & Undetermined & - & - & - & -2.46 & -2.31 & NS & NS & $0.0341,0.0588,0.0010$ \\
\hline 34 & P62334 & $26 \mathrm{~S}$ protease regulatory subunit S10B (Psmc6) & 7.10 & 44.1 & $404,30 \%, 8$ & -1.47 & NS & NS & NS & $0.0078,0.0359,0.1776$ \\
\hline 35 & - & Undetermined & - & - & - & -2.57 & -2.41 & NS & NS & $0.0096,0.0187,0.0002$ \\
\hline 36 & Q9JHI5 & isovaleryl-CoA dehydrogenase (IVD) & 8.53 & 46.3 & $350,20 \%, 7$ & -1.56 & -1.73 & NS & NS & $0.118,0.0354,0.07550$ \\
\hline 37 & Q9CQM9 & Glutaredoxin-3 (Glrx3) & 5.42 & 37.8 & $93.0,7 \%, 2$ & -1.64 & -1.76 & NS & NS & $0.2368,0.0992,0.0010$ \\
\hline 38 & Q9JMD3 & PCTP-like protein (PCTP-L) & 6.67 & 32.9 & $169.0,8 \%, 2$ & NS & NS & NS & NS & $0.0224,0.0711,0.6146$ \\
\hline 39 & - & Undetermined & - & - & - & -1.67 & NS & -1.84 & NS & $0.0002,0.9421,0.7163$ \\
\hline 40 & - & Undetermined & - & - & - & NS & +2.35 & NS & NS & $0.1041,0.0075,0.1830$ \\
\hline 41 & - & Undetermined & - & - & - & -1.97 & -1.85 & NS & NS & $0.1486,0.2342,0.0151$ \\
\hline 42 & P52624 & Uridine phosphorylase 1 (UPase 1) & 6.12 & 34.1 & $101.0,6 \%, 2$ & NS & NS & +3.59 & NS & $0.0096,0.2894,0.2429$ \\
\hline 43 & Q99J99 & 3-mercaptopyruvate sulfurtransferase (MST) & 6.11 & 33.0 & $416,36 \%, 9$ & -1.51 & -1.44 & NS & NS & $0.0075,0.0178,0.2104$ \\
\hline 44 & Q99LC5 & Electron transfer flavoprotein subunit alpha (Alpha-ETF) & 8.62 & 35.0 & $878,49 \%, 13$ & NS & -1.50 & NS & NS & $0.0393,0.0059,0.4695$ \\
\hline 45 & O70435 & Proteasome subunit alpha type-3 (Psma3) & 5.29 & 28.4 & $80.0,10 \%, 2$ & NS & +5.06 & +1.72 & +3.80 & $0.0152,<0.0001,0.211$ \\
\hline 46 & Q9R1P0 & Proteasome subunit alpha type-4 (Psma4) & 7.59 & 29.5 & $231,19 \% ; 4$ & NS & NS & NS & -1.70 & $0.204,0.0167,0.32380$ \\
\hline 47 & Q9JKB1 & Ub carboxyl-terminal hydrolase isozyme L3 (Uchl3) & 4.96 & 26.1 & $142,16 \%, 3$ & NS & NS & NS & +2.35 & $0.7986,0.0105,0.0445$ \\
\hline 48 & Q9Z2U1 & Proteasome subunit alpha type-5 (Psma5) & 4.74 & 26.4 & $87.0,7 \%, 2$ & NS & NS & +1.85 & +2.22 & $0.2666,0.0385,0.0004$ \\
\hline 49 & Q99LX0 & Protein deglycase DJ-1 (DJ-1) & 6.32 & 20.0 & $178,12 \%, 3$ & -1.54 & -1.70 & NS & NS & $0.0036,0.0008,0.4190$ \\
\hline 50 & Q3THE2 & Myosin regulatory light chain 12B (Myl12b) & 4.71 & 19.8 & $105,12 \%, 3$ & NS & NS & NS & NS & $0.0519,0.0117,0.7918$ \\
\hline
\end{tabular}

${ }^{\mathrm{a}}$ Theoretical molecular mass $(\mathrm{Mr})$ and isoelectric point (pI) calculated from the mature protein and amino acid sequence, respectively. 
${ }^{\mathrm{b}} \mathrm{MASCOT}$, algorithm that uses mass spectrometric data to identify proteins from primary sequence databases.

${ }^{\mathrm{c}}$ Number of peptides matched.

${ }^{\mathrm{d} A}$ Average spot volume ratio between two groups. +, upregulated; -, downregulated; NS, not significant. 
Table 2. DAVID functional annotation clusters generated from the list of colonic proteins differentially expressed between the four mice

groups

\begin{tabular}{|c|c|c|c|c|c|c|c|}
\hline & Annotation category & Term & $\begin{array}{l}\text { Enrichment } \\
\text { Score }^{1}\end{array}$ & $\begin{array}{l}\text { Protein } \\
\text { count }\end{array}$ & $P$ value $^{2}$ & Benjamini $^{3}$ & Related genes $^{4}$ \\
\hline \multirow[t]{3}{*}{ Annotation Cluster 1} & SP_PIR_KEYWORDS & Mitochondrion & 4.89 & 11 & $7.0 \mathrm{E}-6$ & $2.2 \mathrm{E}-4$ & $\begin{array}{l}\text { ATP5B, ETFA, GFM1, GFM2, GLUD1, } \\
\text { HSPD1, IMMT, IVD, MPST, TRAP1, VSP4B }\end{array}$ \\
\hline & SP_PIR_KEYWORDS & Transit peptide & & 8 & $1.3 \mathrm{E}-5$ & $3.1 \mathrm{E}-4$ & $\begin{array}{l}\text { ATP5B, ETFA, GFM1, GFM2, GLUD1, } \\
\text { HSPD1, IVD, TRAP1 }\end{array}$ \\
\hline & UP_SEQ_FEATURE & Transit peptide: Mitochondrion & & 8 & $2.4 \mathrm{E}-5$ & $2.5 \mathrm{E}-3$ & $\begin{array}{l}\text { ATP5B, ETFA, GFM1, GFM2, GLUD1, } \\
\text { HSPD1, IVD, TRAP1 }\end{array}$ \\
\hline \multirow[t]{5}{*}{ Annotation Cluster 2} & INTERPRO & Proteasome, alpha-subunit & 2.06 & 3 & $8.2 \mathrm{E}-5$ & $9.2 \mathrm{E}-3$ & PSMA3, PSMA4, PSMA5 \\
\hline & SP_PIR_KEYWORDS & Proteasome & & 4 & $1.2 \mathrm{E}-4$ & $1.9 \mathrm{E}-3$ & PSMA3, PSMA4, PSMA5, PSMC6 \\
\hline & INTERPRO & Proteasome, subunit alpha/beta & & 3 & $5.5 \mathrm{E}-4$ & $3.1 \mathrm{E}-2$ & PSMA3, PSMA4, PSMA5 \\
\hline & KEGG_PATHWAY & Proteasome & & 4 & $6.2 \mathrm{E}-4$ & $1.9 \mathrm{E}-2$ & PSMA3, PSMA4, PSMA5, PSMC6 \\
\hline & SP_PIR_KEYWORDS & Threonine protease & & 3 & $6.4 \mathrm{E}-4$ & $6.0 \mathrm{E}-3$ & PSMA3, PSMA4, PSMA5 \\
\hline \multirow[t]{2}{*}{ Annotation Cluster 3} & SP_PIR_KEYWORDS & gtp-binding & 1.94 & 6 & $2.2 \mathrm{E}-4$ & $2.3 \mathrm{E}-3$ & ADSS, EEF2, GFM1, GFM2, GLUD1,TUBB5 \\
\hline & PANTHER_MF_ALL & Translation elongation factor & & 3 & $5.3 \mathrm{E}-4$ & $2.6 \mathrm{E}-2$ & EEF2, GFM1, GFM2 \\
\hline
\end{tabular}

\footnotetext{
${ }^{1}$ Fold enrichment of the cluster.

${ }^{2} P$ value from modified Fisher's exact test (EASE score).

${ }^{3} P$ value adjusted for multiple testing according to the Benjamini-Hochberg model.

${ }^{4}$ Genes encoding the differentially expressed proteins in Mus Musculus: ADSS - Adenylosuccinate Synthase; ATP5B - ATP Synthase, H+ Transporting, Mitochondrial F1 Complex, Beta Polypeptide; EEF2 - Eukaryotic Translation Elongation Factor 2; ETFA - Electron Transfer Flavoprotein Alpha Subunit; GFM1 - G Elongation Factor Mitochondrial 1; GFM2 Elongation Factor Mitochondrial 2; TRAP1 - Heat shock protein 75 kDa, mitochondrial; GLUD1 - Glutamate Dehydrogenase 1; HSPD1- Heat Shock Protein Family D (Hsp60) Member 1; IMMT - Inner Membrane Mitochondrial Protein; IVD - Isovaleryl-CoA Dehydrogenase; MPST - Mercaptopyruvate Sulfurtransferase; PSMA3 - Proteasome Subunit Alpha 3; PSMA4 - Proteasome Subunit Alpha 4; PSMA5 - Proteasome Subunit Alpha 5; PSMC6 - Proteasome 26S Subunit, ATPase 6; TUBB5 - Tubb5 tubulin, beta 5 class I; VSP4B - Vacuolar protein sorting-associated protein 4B.
} 
For TOC Only

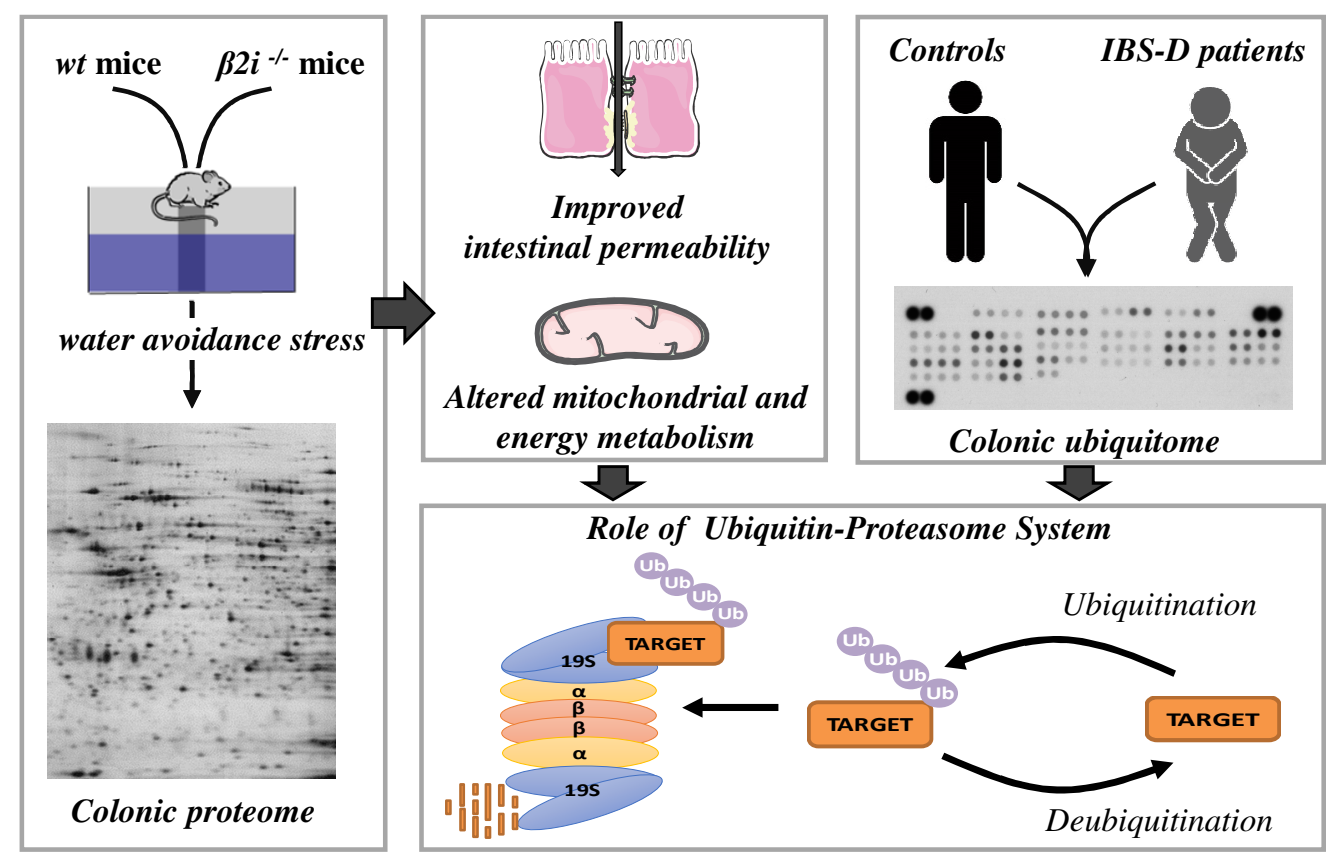

